\title{
Discussion Paper No. 13-023 \\ Cultural Influences on the Fertility Behaviour of First- and Second-generation Immigrants in Germany
}

Holger Stichnoth and Mustafa Yeter

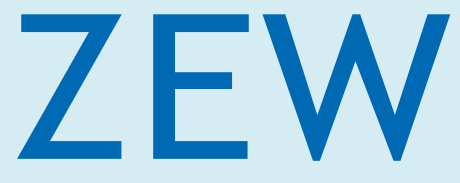

Zentrum für Europäische Wirtschaftsforschung $\mathrm{GmbH}$

Centre for European

Economic Research 



\title{
Discussion Paper No. 13-023 \\ Cultural Influences on the Fertility Behaviour of First- and Second-generation Immigrants in Germany
}

\author{
Holger Stichnoth and Mustafa Yeter
}

Download this ZEW Discussion Paper from our ftp server:

http://ftp.zew.de/pub/zew-docs/dp/dp13023.pdf

Die Discussion Papers dienen einer möglichst schnellen Verbreitung von neueren Forschungsarbeiten des ZEW. Die Beiträge liegen in alleiniger Verantwortung der Autoren und stellen nicht notwendigerweise die Meinung des ZEW dar.

Discussion Papers are intended to make results of ZEW research promptly available to other economists in order to encourage discussion and suggestions for revisions. The authors are solely responsible for the contents which do not necessarily represent the opinion of the ZEW. 


\section{Non-technical summary}

Germany has a lower fertility rate than many other Western countries. The difference in fertility rates is likely to be driven by both socio-economic and institutional factors (e.g., access to childcare) as well as by cultural differences with respect to gender roles and fertility norms. However, disentangling these influences empirically is not straightforward, as both sets of variables likely influence each other.

To deal with this difficulty, the present article focuses on the group of immigrant women and their descendants. It documents that growing up in countries that differ in their fertility rate affects the women's own number of children even if they spend their fertile years under the common institutional setting in Germany. This so called "epidemiological approach" allows relatively clean identification of the cultural influence on fertility. There has been only one such study in the German context so far, which focuses exclusively on first-generation immigrant women. Thanks to a much larger data set (the Mikrozensus 2008 , a reprensentative $1 \%$ sample of the German population), the present article extends the analysis to second-generation immigrants. The influence of fertility rates in the countries of ancestry is still perceptible here, which is consistent with intergenerational transmission of fertility norms. However, the influence is weaker than in the first generation and still weaker if one parent is from Germany or if the parents are immigrants from two different countries.

From a methodological point of view, the present article makes three contributions: First, the large data set makes it possible to study completed fertility by concentrating on women aged 45 and above and to restrict the sample to women who arrived in Germany below the age of 18 and therefore spent most of their fertile years in the country of migration. Second, the large number of observations allows comparing women from the same country of origin who were born in different years or arrived in Germany at different points in time. This within country approach mitigates concerns about unobserved influences on fertility that might be correlated with the country of origin. Finally, the study goes beyond the usual measure of home country influences (total fertility rates) and additionally considers completed cohort fertility rates and direct measures of fertility norms. 


\section{Das Wichtigste in Kürze (German summary)}

Deutschland weist im internationalen Vergleich eine niedrige Geburtenrate auf. Die Ursachen sind vermutlich sowohl in der Ausgestaltung der institutionellen Rahmenbedingungen (insbesondere fehlenden Kinderbetreuungsplätzen) als auch in den vorherrschenden Geschlechter- und Fertilitätsnormen zu suchen. Da sich beide Gruppen von Einflussfaktoren wechselseitig beeinflussen, ist eine empirische Abschätzung ihrer spezifischen Wirkungen jedoch schwierig.

Um dieser Schwierigkeit zu begegnen, verwendet der vorliegende Artikel einen "epidemiologischen Ansatz", mit dessen Hilfe sich institutionelle und kulturelle Einflüsse so weit wie möglich trennen lassen. Die Analyse konzentriert sich auf Einwanderinnen und dokumentiert, dass eine Prägung durch unterschiedlich hohe Geburtenraten in den Heimatländern auch dann einen Einfluss auf die eigene Kinderzahl hat, wenn die fruchtbaren Jahre in Deutschland, also unter ähnlichen institutionellen Rahmenbedingungen, verbracht werden. Für Deutschland liegt bisher erst eine Studie vor, die sich auf die Einwanderinnen der ersten Generation beschränkt. Der Beitrag dieses Artikels besteht darin, dass aufgrund einer deutlich größeren Datenbasis (verwendet wird der Mikrozensus 2008, eine einprozentige Stichprobe der Haushalte in Deutschland) auch die Einwanderinnen der zweiten Generation in die Analyse eingeschlossen werden können. Es zeigt sich, dass auch hier die Geburtenraten in den Herkunftsländern (in diesem Fall der Eltern) einen Einfluss auf die eigene Kinderzahl haben, was für eine kulturelle Transmission der Geschlechter- und Fertilitätsnormen spricht. Der Einfluss ist jedoch schwächer als in der ersten Generation und fällt noch einmal schwächer aus, wenn die beiden Elternteile aus unterschiedlichen Herkunftsländern stammen oder ein Elternteil in Deutschland geboren wurde.

Methodisch stellt der vorliegende Artikel in dreierlei Hinsicht eine Verbesserung dar: Die große Datenbasis erlaubt es erstens, sich auf Frauen ab 45 Jahren, d.h. mit weitgehend abgeschlossenen Fertilitätsbiografien, zu konzentrieren. Außerdem werden in der ersten Generation nur die Frauen herangezogen, die bis zu einem Alter von 18 Jahren nach Deutschland eingewandert sind, also tatsächlich den Großteil ihrer fruchtbaren Jahre im Zielland verbracht haben. Zweitens ist es möglich, nur Frauen aus dem gleichen Herkunftsland miteinander zu vergleichen. Damit kann dem berechtigten Einwand, dass sich Frauen, die aus Ländern mit unterschiedlich hohen Geburtenraten stammen, auch in weiteren fertilitätsrelevanten Merkmalen unterscheiden, begegnet werden. Drittens werden als Maß für die Fertilität im Herkunftsland nicht nur die periodenspezifische zusammengefasste Geburtenziffer, sondern auch ein Indikator für die Kohortenfertilität und direkte Informationen zu den Fertilitätsnormen herangezogen. 


\title{
Cultural influences on the fertility behaviour of first- and second-generation immigrants in Germany
}

\author{
Holger Stichnoth ${ }^{1}$ \\ ZEW Mannheim
}

\author{
Mustafa Yeter $^{2}$ \\ ZEW Mannheim
}

April 22, 2013

\begin{abstract}
Based on a $1 \%$ sample of the German population, we study how fertility rates in the country of origin - a proxy for cultural imprint - influence the fertility outcomes of first- and second-generation female immigrants. We use both total fertility rates in the year of migration and a new measure of completed cohort fertility rates in the countries of origin as well as direct survey measures of fertility norms. Our large data set allows us to focus on a relatively narrow range for age at migration and to estimate models that rely on within-country variation only, leading to more credible identification. We find a statistically significant, sizeable and robust effect of country-of-origin fertility rates on fertility outcomes. The effect is strongest for the first generation and becomes weaker, though still statistically significant, for "generation 1.5" (migrants arriving as children) and the second generation. It is stronger for women with low education and for women who live with a partner from the same country of origin.
\end{abstract}

JEL classification: J13; J15; J16

Keywords: Immigration; fertility; assimilation; intergenerational transmission; Germany

\footnotetext{
${ }^{1}$ Corresponding author. Address: ZEW Centre for European Economic Research, P.O. Box 103443, 68034 Mannheim, Germany. E-Mail: stichnoth@zew.de. We would like to thank Holger Bonin, Christina Gathmann, Friedrich Heinemann, Tanja Hennighausen, Arne Jonas Warnke and participants at seminars in Mannheim and Freiburg as well as at the NORFACE migration conference (UCL London, April 2013) for helping us to improve the paper.

${ }^{2}$ Address: ZEW Centre for European Economic Research, P.O. Box 103443, 68034 Mannheim, Germany. E-Mail: yeter@zew.de
} 


\section{Introduction}

Fertility rates differ considerably across both countries and time. Notable differences exist even between Western countries. While countries such as Germany, Italy or Spain currently exhibit total fertility rates (TFR) of about 1.4, fertility rates in France, Ireland, the UK and the US are close to the replacement rate of about 2.1 children per woman. These differences in fertility rates have long-run consequences for both the size and the age structure of the population, with important and much-debated economic repercussions on the pension system and on the size and the average productivity of the workforce.

The differences in fertility rates are driven by both socio-economic and institutional factors (different opportunity costs of child-rearing resulting from differences in female human capital, access to childcare, or family policies) as well as by cultural differences with respect to gender roles and fertility norms. However, using cross-country variation in fertility rates to disentangle the influence of the cultural imprint on the one hand and socio-economic and institutional factors on the other hand is not straightforward, as both sets of variables likely influence each other.

While controlled experiments across different cultural settings (Henrich et al., 2001) can shed some light on the influence of culture on individual behaviour, this approach has obvious limitations for the study of fertility. Here, relatively clean identification of cultural effects can be achieved by using an "epidemiological approach" (for surveys, see Fernández, 2007; 2008; 2011; Guiso et al., 2006), which relates fertility or labour market outcomes of immigrants or their descendants to the corresponding outcome measures (or, in some cases, to attitudinal data on gender norms) in the countries of origin or countries of ancestry. ${ }^{1}$ The hypothesis is that immigrants were influenced by the gender norms of their countries of origin before they migrated, and that these norms are then partly

\footnotetext{
${ }^{1}$ An alternative strand of the literature employs a spatial regression discontinuity approach to study the effect of culture on behaviour. Eugster et al. (2011) use the relatively sharp language borders within Swiss cantons to identify the effect of culture on the demand for social insurance; Basten and Betz (2012) study the effect of religion. In yet unpublished work, Steinhauer (2012) uses the same spatial RDD approach to study childlessness and female labour supply.
} 
transmitted to their descendants. Since the different immigrant groups face the same overall institutional setting in the host country, the influence of institutions on fertility outcomes can be controlled for and the impact of home country culture can be isolated. This paper uses the epidemiological approach to study cultural influences on the fertility behaviour of first- and second-generation immigrants in Germany. ${ }^{2}$ As noted above, Germany currently has one of the lowest fertility rates among Western industrialised countries. Focusing on Germany is also interesting as it has been a country of large-scale immigration since the early 1960s. According to figures from the 2011 Mikrozensus, 10.7 million people living in Germany were born abroad (13\% of the population), and an additional 5.3 million have at least one parent who was born abroad. The links between immigration and fertility are controversially discussed in Germany. While some see immigration as a remedy against the population decline resulting from below replacement fertility rates, others fear the political and cultural consequences of higher birth rates among immigrants and their descendants.

Despite this discussion, there have been very few studies on the link between immigration and fertility in Germany. In particular, little is known about the second generation of immigrants. This is mainly due to data limitations. While household surveys such as the Socio-Economic Panel (SOEP) contain the necessary information on the country of birth of respondents and their parents, sample sizes are too small for a detailed analysis of the second and, for some aspects, even the first generation of immigrants. In the present study, we therefore use data from the 2008 wave of the German Mikrozensus, an annual

\footnotetext{
${ }^{2}$ Fernández and Fogli (2006), Fernández and Fogli (2009) and Blau et al. (2013) use the epidemiological approach to study cultural influences on the fertility behaviour of second-generation immigrants in the United States. Cygan-Rehm (2011) applies the approach to first-generation immigrants in Germany. The approach has also been applied to other outcome variables. Blau et al. (2011) and Blau and Kahn (2011) investigate cultural influences on the labour supply of immigrants in the United States; Gevrek et al. (2011) and Kok et al. (2011) study the labour supply of second-generation female immigrants in Canada and female immigrants in the Netherlands, respectively. Luttmer and Singhal (2011) document the influence of home country culture on the preferences for redistribution among immigrants in a number of European countries, and Furtado et al. (2013) apply the approach to divorce rates of European immigrants in the United States. Algan and Cahuc (2010) follow a related strategy and use variation across countries and cohorts in the inherited trust report by descendants of US immigrants to proxy for trust in their countries of ancestry.
} 
$1 \%$ sample of the population. The 2008 wave is the first and currently the only wave that allows both the identification of naturalised immigrants (possible only since 2005) and has information on the total number of births, as opposed to information on the number of children currently living in the household. ${ }^{3}$

We merge these data with country information on total fertility rates (compiled by the UN and the World Bank) to study whether the exposure to a different fertility rate prior to migration has an effect on fertility behaviour under the common institutional setting in Germany. We estimate models for the total number of children for women aged 45 or above who are either immigrants (1st generation) or who were born in Germany but have at least one parent who is an immigrant or who was born as a foreigner in Germany (2nd and higher generation).

The paper that is most closely related to ours is by Cygan-Rehm (2011). She finds an effect of total fertility rates in the country of origin on completed fertility of immigrant women using pooled data from three waves of the SOEP. Our study extends the analysis to the second generation. Comparing results for the different generations of immigrants then provides indirect evidence about the strength of cultural transmission versus assimilation of the common host country norms. Moreover, we study whether the effect is stronger in the second generation if both parents are from the same country of origin.

Another contribution of the present study is the focus on the variation within countries of origin. We exploit the fact that immigrants have arrived in different years and were therefore exposed to different fertility environments prior to migration. In the second generation, longitudinal variation arises from different years of birth (parents' year of arrival is unfortunately not observed in the Mikrozensus). The approach mitigates concerns about (time-constant) omitted country-level variables that are correlated with the country-of-origin fertility rates and that also exert an independent influence on fertility

\footnotetext{
${ }^{3}$ Recent studies on second generation immigrants in Germany using the Mikrozensus have focused on educational attainment (Riphahn, 2003; 2005; Luthra, 2010a) and employment (Luthra, 2010b). Avitabile et al. (2012) and Sajons (2011a;b) use the Mikrozensus to study the effects of a reform in the German citizenship law on the return migration and integration decisions of first-generation immigrants.
} 
outcomes in Germany. One example is the distance between Germany and the country of origin, which likely has an impact on fertility behaviour via the intensity of contacts with the country of origin.

Unlike some previous studies, we do not only control for age at migration, but also restrict the sample to women who arrived until the age of 18. Including all women regardless of their age at arrival would invalidate the identification strategy as women who came at a later age will have spent most or even all of their fertile years in the country of origin, making it impossible to disentangle the effects of culture and institutions. We study how sensitive the results are with respect to different upper limits for age at migration, and how this sensitivity differs between pooled and within-country models.

Finally, we also exploit variation in direct measures of fertility norms from the World Values Survey and in completed cohort fertility rates in the country of origin, using data recently compiled by Myrskylä et al. (2012). The latter measure has not been used in the economics literature before, as previous studies have focused on the more widely available total fertility rates. The total fertility rate is defined as the number of children that would be born to a woman if she were to live to the end of her childbearing years and, at each age, had a probability of giving birth that is equal to the current age-specific fertility rates. Consequently, the TFR only presents a synthetic fertility measure that will deviate from the actual numbers to the extent that cohorts differ in the timing of births. In contrast, completed cohort fertility rates measure the number of children actually born to women of a specific cohort until the end of their childbearing years. To our knowledge, there is currently no theory or consensus about which of the two is the better proxy for country-of-origin influences on fertility. Using the total fertility rate as a proxy assumes that the women took a snapshot (which then remains fixed) of the fertility behaviour of women of all relevant ages in the year of migration. In contrast, the cohort fertility rate will be preferable as a proxy if the immigrants' reference group are those people of the same birth cohort who did not migrate. This latter measure assumes that immigrant women in Germany remain in contact with their country of origin so that they receive 
updates of the evolution of fertility behaviour there.

Our main results are as follows: the higher the total fertility rate in the country of origin in the year of migration, the higher the number of children of immigrant women in Germany. This also holds after controlling for observable differences (e.g., with respect to education) between women of different origin countries and migration years, and also when only the temporal variation is used, thereby netting out time-constant factors at the country level. We find that if country-of-origin TFR in the year of migration is higher by one child per woman (this is about equal to one standard deviation), the completed fertility rate of immigrant women in Germany is higher by between 0.32 and 1.10 children per woman (between $14 \%$ and $47 \%$ of the average for completed fertility among immigrant women), depending on the upper limit for age at migration. For all but the smallest sample (restricted to women arriving at age 15), the coefficient on the total fertility rate is highly statistically significant in the pooled model. The models that exploit only variation within countries of origin point to a slightly larger influence of country-of-origin fertility rates on own fertility behaviour than the pooled models. Despite the loss in precision, the coefficients in the within model remain statistically significant in most cases. We find that controlling for age at migration even within a given age bracket is of greater importance in the within specifications than in the pooled model, and that this additional control is more important if a wide age bracket is chosen (as in some previous studies that included all women regardless of their age at migration). The positive relationship between total fertility rates and completed fertility among immigrant women survives in a large number of alternative specifications. The influence appears to work mainly through the intensive margin and less through the probability of having children. The effect is strongest in the first generation and becomes weaker for "generation 1.5" (migrants arriving as children) and the second generation. In the second generation, the effect is stronger if both parents are from the same country of origin.

Moreover, we find that the influence is strongest for women with low education and for 
women with a partner from the same country of origin. Especially in the latter case, however, the results should be interpreted as descriptive as a stronger attachment to one's origin will both affect partner choice and the degree to which own fertility choices are influenced by the fertility rates in the country of origin.

Concerning the different measures of influences from the country of origin, we find a positive effect not only for total fertility rates in the year of migration but also for completed cohort fertility rates of people that were born in the same year as the migrants but remained in the countries of origin. In contrast, when fertility norms from the 1990 wave of the World Values Survey (hence years or even decades after most women in our sample arrived in Germany) are used as proxies instead, the relationship is instable and in most cases no longer statistically significant.

\section{Data description}

Our main data set is the Scientific Use File of the 2008 wave of the Mikrozensus, an annual survey carried out by the German Statistical Office on a representative 1\% sample of German households. ${ }^{4}$ In addition to the large sample size, the Mikrozensus has the advantage that people are legally obliged to answer the core set of questions (including most of the variables used in our study, but unfortunately not the question on the total number of births), so that unit and item non-response is less of an issue than in other surveys. The drawback is that the set of possible covariates is smaller than in the SOEP or in specialised small-sample surveys with a focus on migration or family issues. Nevertheless, the advantages predominate since the large sample size makes it possible to study the first generation of immigrants in more detail and under weaker identification assumptions than in previous work. Moreover, the Mikrozensus allows us to apply the epidemiological approach to the fertility behaviour of second-generation immigrant

\footnotetext{
${ }^{4}$ Full censuses are rare in Germany. The 1987 census was for West Germany only and the data from the 2011 census are not available yet.
} 
women, for whom the sample size is too small in the SOEP.

We distinguish between three generations in our analysis of cultural influences on fertility behaviour. The sample for the first generation comprises women who were born abroad, immigrated to Germany at age 15 or above and were residing in Germany in 2008. The related "generation 1.5" was also born abroad but immigrated before age 15 . Distinguishing these two groups is common in the migration literature; the precise cut-off age is of course somewhat arbitrary. Our choice of age 15 follows Milewski (2007) and Cygan-Rehm (2011), but our results still hold for cut-offs of 6 or 12 years of age. Finally, the second generation is made up of people who were born in Germany as a foreigner or who were born with German nationality but have at least one parent who immigrated or who was born as a foreigner in Germany.

The Mikrozensus allows clean identification of these immigrant generations only since 2005. In earlier waves, only respondents with foreign nationality were asked about their country of birth. As a result, naturalised immigrants could not be identified. Although naturalisation rates for immigrants from the traditional "guest-worker" countries have long been low, this has changed considerably following a new Citizenship Law in 2000. ${ }^{5}$ Moreover, many of the so called "Spätaussiedler" (people with German ancestry from Eastern Europe and the former Soviet Union) obtained a German passport on their arrival or shortly afterwards.

While this first obstacle to a study of immigrant fertility was lifted in 2005, the measurement of fertility poses a second challenge. In fact, the 2008 wave of the Mikrozensus is currently the only one that contains information on the total number of children a woman has given birth to. Both earlier and later waves instead asked about the children living in the household at the time of the survey, a measure that would not be well-suited for our purpose. Depending on the mother's age, some children will likely have moved out already, especially as we focus on respondents who had reached the end of their fertile

\footnotetext{
${ }^{5}$ See, for instance, Avitabile et al. (2012) and Sajons (2011a;b).
} 
years by the time of the survey. Relying on the number of children in the household would therefore lead to a systematic underestimation of the completed fertility rate. The bias would be largest for mothers who had their children at a relatively young age. ${ }^{6}$

In our main specification, which focuses on completed fertility, we set the lower age limit to 45 years. Since our earliest country-level information is from 1950, we drop all women who were born before 1950 (second generation) or who migrated to Germany before that year (generations 1 and 1.5). We also drop observations with missing information on at least one of the variables used in our models.

Finally, in our main specification we include only those women from the first generation who arrived before the age of 18 . As discussed in more detail below, age-specific fertility patterns for the countries of origin clearly suggest that a non-negligible share of first births occurred when the women were in their early 20s or even younger. Keeping all women regardless of their age at arrival would therefore invalidate our empirical strategy, which proposes to isolate the effect of early exposure to a different fertility environment by comparing fertility behaviour under the common German institutional setting.

Our estimation sample consists of 529 women from the first generation, 495 women from generation 1.5, and 3532 women from the second or higher generations. The women are from 18 different countries of origin. ${ }^{7}$ Summary statistics by country of origin and

\footnotetext{
${ }^{6}$ With the new question, the data situation has improved but is still not ideal (for a survey on German fertility data, see Kreyenfeld et al., 2011). First, the age of the children is available only for those children still living in the household. This means that we cannot convincingly control for whether first-generation women already had children before coming to Germany. Moreover, the question about the total number of births was asked in the voluntary part of the Mikrozensus. In the questionnaire, this item was split from the mandatory questions about the people currently living in the household. Probably for this reason, item non-response was relatively high, and the German Statistical Office developed a procedure to impute answers whenever possible. After the imputation, information on the total number of children is missing for about $7 \%$ of the women in the Mikrozensus. Reassuringly, Pötzsch (2010) shows that the fertility data from the Mikrozensus 2008 are close to the figures from official birth statistics.

${ }^{7}$ In the Mikrozensus, countries of origins with few observations are grouped into larger categories such as "sub-Saharan Africa" or "South America". Observations from these countries were dropped as merging in aggregate fertility information would only be possible under strong assumptions in these cases, especially since other data sources based on which year-specific arrival patterns by country could be inferred also use similarly coarse groupings. As part of the robustness checks, we further limited the estimation samples to countries with at least 100 observations (first generation) or 15 observations (second generation). The lower limit of 15 observations for the second generation follows Fernández and Fogli (2009).
} 
generation are shown in the Appendix.

First generation Completed fertility in the first generation of immigrants (Table A.1) varies between 1.3 (Austria) and 3.0 (Turkey) children per woman. ${ }^{8}$ Women from Greece and Italy have on average 2.1 and 2.4 children, respectively, women from the three former socialist countries (Poland, former Soviet Union, former Yugoslavia) have lower rates of between 1.4 and 1.9 children per woman. ${ }^{9}$ A similar ranking arises when the share of women without children is considered. Only $2 \%$ of immigrant women from Turkey in our sample remained childless, while this share stands at $22 \%$ for immigrants from Austria.

Immigrant women who do not have German nationality have more children on average. Women who live with a partner from the same country of origin tend to have more children than those with a partner from a different origin (including Germany) and those who, at the time of the survey in 2008, do not live with a partner.

There is a strongly negative relationship between the level of education and completed fertility. While immigrant women with a tertiary degree have on average 1.6 children, the corresponding figure for the lowest educational group stands at 2.6. There is also a large difference in the share of childless women. As Table A.2 shows, $71 \%$ of immigrant women in our sample fall into the lowest educational category, and only $3 \%$ possess a tertiary degree. There are considerable differences in educational attainment by country of origin that need to be controlled for in the estimation.

The share of women who are married at the time of the survey varies between slightly more than 70\% (former Soviet Union, former Yugoslavia) and about 85\% (Italy, Turkey). There are also large differences when it comes to the origin of the partner. Women from Turkey and Italy are considerably more likely to be living with a partner from the same country of origin compared to women from Eastern Europe or from Austria.

\footnotetext{
${ }^{8}$ In our discussion of the table, we ignore countries with very few observations.

${ }^{9}$ The broad ranking and the overall mean are similar to Cygan-Rehm (2011, Table 2), although some of the numbers differ. They are not directly comparable, however, as Cygan-Rehm pools information from 1991, 1999 and 2007 and includes all women regardless of their age at migration.
} 
Finally, the country of origin is correlated with differences in citizenship. While more than $80 \%$ of women from Poland or the former Soviet Union possess German citizenship (either exclusively or, in some cases, together with their nationality of origin), only about a quarter of women from Turkey or the former Yugoslavia do so. The share is even lower for women from Greece or Italy.

As Table A.3 shows, women from the early "guest worker" countries Italy, Greece and the former Yugoslavia have on average lived in Germany for more than 35 years. ${ }^{10}$ Typically the men arrived first and, if they decided to stay, their wives joined them a few years later. Immigration from Turkey began slightly later, and women from Turkey mainly arrived in the 1970s. Women from Eastern Europe arrived even later.

Important for our empirical strategy, there is considerable variation in the time of arrival even within countries of origin. For each country, there are some women who came in the 1950s and others who arrived only in the late 1970s. More recent immigrants are not included since we restrict the sample to women who were at least 45 years old at the time of the survey in 2008 and who migrated before the age of 18. As a consequence, 1981 is the most recent year of arrival.

Generations 1.5 and 2 Studying completed fertility with a lower age limit of 45 years results in a very small sample size in the second generation. We therefore consider two alternative samples. In the first one, we keep the focus on the second generation but reduce the lower age limit to 15 years, the earliest age for which fertility information is available in the Mikrozensus. In the second alternative sample, we keep the age limit of 45 but combine the second generation with generation 1.5. That is, we estimate models of completed fertility for women who either immigrated before the age of 15 or who were born in Germany and have at least one parent who immigrated or was born as a foreigner

\footnotetext{
${ }^{10}$ This is conditional on observing the women in 2008 , so return migrants are not included and these numbers should not be interpreted as the expected duration of stay for all migrants from these countries.
} 


\section{in Germany. ${ }^{11}$}

In our main specification, we use the one-dimensional measure of the country of origin provided by the Mikrozensus. ${ }^{12}$ For members of the second generation who were born in Germany as a foreigner, the Mikrozensus uses nationality to define the origin (either current nationality or, if a person has acquired German nationality since, nationality prior to naturalisation). The case is relatively frequent in Germany due to the German citizenship law which favours the "right of the blood" (ius sanguinis) over the "right of the soil" (ius soli). In our sample, $65 \%$ of second-generation women were born in Germany as foreigners.

Those members of the second generation who had German nationality at birth are classified according to their parents' origin. If only one parent is of immigrant background (i.e., is an immigrant or was born in Germany as a foreigner), then the country of origin of this parent is used. In the relatively rare cases in which the parents are from different backgrounds, the Mikrozensus bases its classification on the background of the father only. ${ }^{13}$ Note that for individuals who already had German nationality at birth, identifying members of the second generation is generally only possible when they still live with at least one of their parents. Otherwise, information on ancestry is only available for a $10 \%$ subsample in which people were asked about whether their parents have or had foreign nationality. Unlike in the main questionnaire, answering this question is voluntary.

Tables A.4 to A.7 in the Appendix provide summary statistics for the second generation. ${ }^{14}$ In the sample including immigrants aged 15 and above, the information on the

\footnotetext{
${ }^{11}$ In the latter case, the person would be part of the third generation. The Mikrozensus does not allow us to distinguish between the second and higher generations in all cases. However, given German migration history and the lower age limit of 45 , there are most likely only very few members of the third generation in our sample. Even with a lower age limit of 15, third-generation women are likely to be in the minority. For simplicity, we refer to all these women as second generation throughout.

${ }^{12}$ In an alternative specification for a smaller sample, we also exploit information on mixed origin that we constructed from the data.

${ }^{13}$ When studying children of mixed origin, we therefore go back to the original data in order to identify both origins.

${ }^{14}$ The summary statistics for the sample in which we combine generations 1.5 and 2 (both with age
} 
number of children has to be interpreted carefully since the average age differs considerably depending on country of origin. The mean age ranges from about 20 years (women of Polish or Vietnamese origin) to 30 years (Austrian or Spanish origin). Women of Turkish origin, by far the largest group, are on average 24 years old. This mainly reflects the arrival pattern of the first generation mentioned above. The differences in the number of children are therefore clearly confounded by the age differences, which suggests that controlling for age will be more important in the younger sample than in a model for completed fertility estimated on a sample of women aged 45 and above.

For this older sample (Table A.6), the fertility differences by country of origin are smaller than in the first generation. Women of Turkish origin still have the highest fertility rates $^{15}$, but the mean number of children is only 2.3, well below the value of 3.0 in the first generation. The patterns with respect to marriage, origin of the partner, education and citizenship also tend to persist in the second generation, but there is again both a trend towards the German average and a reduction in the variance across countries of origin. Note, however, that the figures are based on a very small sample with at most 16 observations per country of origin.

Country-level data We merge the individual- and household-level data from the Mikrozensus with information at the country level from several data sources. Total fertility rates are available on an annual basis from the World Bank's data base of World Development Indicators (World Bank, 2012). The earliest TFR values are for 1960. We extend the data further back by adding observations for 1950-1955 and for 1955-1960 from the United Nations Population Division (United Nations Population Division, 2011). Figure A.1 shows how fertility has evolved since 1950 for the countries of origin included in our estimations. (We only show the main countries of origin here.) There is considerable variation both across countries and across time. A majority of countries in most years

\footnotetext{
limit 45) are available upon request.

${ }^{15}$ The fertility rates for women from Afghanistan is even higher, but the mean is based on one observation only.
} 
exhibited higher total fertility rates than Germany. Turkey stands out for experiencing both by far the highest levels of TFR in the period considered and the largest absolute reduction, from about six children per woman in the 1950s and early 1960s down to about three children in the early 1990s. Note, however, that with an age limit of 45 in 2008 and a maximum age at arrival of 18, 1981 is the latest year that we consider in the main specification. Two other countries in our sample that have registered large declines in fertility over a relatively short period of time are Spain after the mid-1970s and Russia after the late 1980s.

As an additional proxy for country-of-origin fertility norms, we use cohort fertility rates compiled by Myrskylä et al. (2012). Table A.8 in the Appendix shows the cohort fertility rates for the countries in our sample. The completed fertility rates are for 2009 (hence very close to our survey year 2008). ${ }^{16}$ Unfortunately, Turkey, the most important country of origin, is not part of the compilation by Myrskylä et al. (2012), but we managed to construct values for two cohorts by going back to original Turkish sources. ${ }^{17}$ As cohort fertility rates are available for only six (or, in the case of Turkey, two) birth cohorts, we linearly interpolate for the remaining years when merging these data with the Mikrozensus.

Finally, we use direct evidence on fertility norms from four questions in the 1990 wave of the European Values Survey (EVS) and the World Values Survey (WVS). ${ }^{18}$ This is the earliest year that we can use as only two of our countries of origin (Italy and Spain) participated in the first wave of 1981. Unfortunately, this means that the information on fertility norms was measured almost ten years after the last migration cohort included in

\footnotetext{
${ }^{16}$ For the younger cohorts, the values compiled by Myrskylä et al. are partly based on projections for the remaining fertile years.

${ }^{17}$ We construct cohort fertility rates for 1950 and 1960 based on the reports for the Turkey Demographic and Health Surveys of 1998 and 2008 (Hacettepe University Institute of Population Studies, 1999; 2009). Each survey report has a table with information on "Children ever born and children surviving" by age group (Tables 3.5 and 4.6 in the reports for 1998 and 2008, respectively). We use the value for women aged 45-49, which corresponds to the birth years 1949-1953 and 1959-1963, respectively. In Table A.8, these values are assigned to the years 1950 and 1960.

${ }^{18}$ The 1990 survey of the WVS is a replication of the original EVS survey for the same year. See http://www. worldvaluessurvey.org for further information. The values for "Yugoslavia" are from a 1992 survey in Slovenia.
} 
our sample.

The questions ask about the ideal number of children (between "none" and "10 or more"), the importance of children for a successful marriage ${ }^{19}$ and for personal fulfillment ${ }^{20}$ and about whether "women really want a home and children" 21 . We recode the variables so that higher values stand for a greater importance attached to children. The four variables are positively correlated (see Table A.9 in the Appendix). Figure A.2 shows the weighted country averages that will be used in the estimation. ${ }^{22}$ Poland and Russia are the two countries that had the most traditional views about fertility norms in 1990, whereas China, the United States, and Austria tend to be among the countries with the least traditional views. In Turkey, a relatively high percentage of respondents declared that "a women has to have children to be fulfilled" (this is the variable with the largest variation in percentage terms), but, surprisingly perhaps, the ideal number of children is among the lowest among the countries considered here. As Figure A.3 shows, there is some evidence of a positive relationship between fertility norms as reported in the 1990 WVS and the total fertility rate in the same year. Turkey and China appear to be outliers in the question on the ideal number of children.

\section{$3 \quad$ Empirical Strategy}

The objective of this paper is to find out whether the exposure to or transmission of different cultural norms and beliefs has an effect on own fertility behaviour even under a

\footnotetext{
${ }^{19}$ The precise wording is the following: "Here is a list of things which some people think make for a successful marriage. Please tell me, for each one, whether you think it is very important, rather important or not very important for a successful marriage." "Children" is one of 13 items. There are three answer categories: "very important", "rather important", "not very important".

20 "Do you think that a woman has to have children in order to be fulfilled or is this not necessary?" We keep the two answer categories "needs children" and "not necessary" and recode "don't know" as missing.

21 "People talk about the changing roles of men and women today. For each of the following statements I read out, can you tell me how much you agree with each. Please use the responses on this card." There are six statements, one of which reads "A job is alright but what most women really want is a home and children". The four answer categories are "strongly agree", "agree", "disagree" and "strongly disagree".

${ }^{22}$ Some countries used in our main model did not take part in the 1990 wave of the EVS/WVS and are therefore missing from the figure. In the Turkish survey, only two of the four questions were asked.
} 
common institutional setting. Our outcome of interest is completed fertility, the number of children at the end of the fertile period.

Observing these fertility norms directly would allow us to test for a cultural effect. Unfortunately, we only have data on fertility norms for a single cross-section of the World Values Survey for 1990, years after most migrants came to Germany. Because of this time lag, we use these data only in a robustness check and, following the literature, focus on observed fertility rates in the country of origin in our main specification instead. We follow an epidemiological approach in which we compare completed fertility of immigrants who arrived from different countries and at different points in time and spent their fertile years under the common institutional setting in Germany. To find out about the intergenerational transmission of this exposure effect, we also study fertility outcomes for the children of these immigrants.

Figure 1 illustrates the empirical strategy. Immigrants were exposed to the fertility rates in their respective countries before migrating. These fertility rates result from the complex interplay between fertility norms and institutions such as child care or child benefits. After migration, immigrants from different countries of origin face a common institutional setting. The previous exposure to different fertility rates is then only relevant for individual fertility choices insofar as it has influenced immigrants' fertility norms. As illustrated in the figure, these norms will be partly transmitted to the children of immigrants.

Which fertility rate to use is open to discussion. The total fertility rate that is typically used in the literature is a snapshot of fertility behaviour at the time of departure. As an alternative, we use completed fertility rates of people from the same birth cohort as the migrant. To the best of our knowledge, this measure has not been used in the literature before. $^{23}$ In both cases, we want to find out whether fertility rates in their

\footnotetext{
${ }^{23}$ One could also think of measuring these fertility rates at a subnational level, as many immigrants from Italy originated from the South and many Turks came from the eastern regions of Turkey. Unfortunately, the Mikrozensus has no information on the region of origin, however. Moreover, regional year-specific measures of fertility are difficult to obtain.
} 
countries of origin have an effect on the fertility behaviour of migrants even when they live under the common German institutional setting. If people from different origins or who arrived at different points in time make different fertility choices while in Germany (after adjustment for other differences), the difference in own fertility will be attributed to the different fertility rates to which they were exposed prior to migration.

Assuming a model that is linear in parameters, we estimate the following equation:

$$
\text { Children }_{i c s t}=\beta_{0}+\beta_{\mathbf{1}}^{\prime} \mathbf{x}_{\mathbf{i}}+\beta_{2} \text { FertilityRate }_{c t}+f_{c}+f_{s}+\varepsilon_{i c s t}
$$

where Children icst $_{\text {is }}$ the number of children (at the end of her fertile years) of woman $i$ from country of origin $c$ who arrived in Germany in year $t$ and lives in federal state $s$ at the time of the survey. FertilityRate $c$ measures the fertility rate in country $c$ in the year of migration and is our regressor of interest. ${ }^{24} f_{c}$ is a country indicator that captures unobserved influences at the level of the country of origin that are constant across years of arrival. $f_{s}$ is an indicator for the federal state which attempts to control for the considerable regional differences in access to childcare. ${ }^{25} x_{i}$ is a vector of control variables measured at the individual level. $\varepsilon_{i c s t}$ captures measurement error in the covariates as well as unobserved influences on the fertility outcome. We assume that the error terms are potentially correlated within cells formed by country of origin and year of arrival and uncorrelated otherwise. The model is estimated using Ordinary Least Squares. As part of the robustness checks, we alternatively estimate count data and Tobit models for completed fertility, and probit models for the probability of having at least one child.

Some of the assumptions underlying the empirical strategy deserve further discussion, in particular regarding the first generation. First, to make the assumption that all other

\footnotetext{
${ }^{24}$ In some specifications, we use the cohort fertility rate of women from the same birth cohort or cross-sectional variation in fertility norms from the 1990 World Values survey instead. For the second generation, we use year of birth instead of year of migration; see the discussion below.

${ }^{25}$ There are 16 federal states (Bundesländer) in Germany. A finer distinction at the municipal level would have been desirable. Unfortunately, the Scientific Use File of the Mikrozensus does not contain this detailed regional information.
} 
things are equal more credible, we control for age and age at migration as well as for the level of education which, as noted above, is strongly correlated both with fertility outcomes and with country of origin. As the survey year is the same for all women, controlling for age and age at migration is equivalent to a linear control for year of arrival and therefore adjusts for changes in the German institutional setting over time. In alternative specifications, we also control for whether the woman lives with a partner (and, if yes, whether the partner is from the same origin) as well as for marital status, nationality, labour market participation and household income. We did not include these variables in our main specification as we believe that they are all, to varying degrees, jointly determined with a woman's fertility choices. ${ }^{26}$

Unlike previous studies, we additionally deal with the problem of unobserved heterogeneity by exploiting the variation within countries only. In our model with country fixed effects, the identifying variation comes from women from the same country of origin arriving in different years. Potential country-level confounders which are constant over time are therefore controlled for. One example is the distance between the country of origin and Germany.

The within models also mitigate concerns about differences in the institutional settings across immigrant groups in Germany. Further controlling for or interacting country of origin fertility rates with the share of people from the same origin in the neighbourhood (as in Fernández and Fogli (2009)) is precluded by the lack of detailed regional information in the Mikrozensus. Likewise, one cannot control for language ability, which could be relevant to the extent that immigrants' knowledge about the institutional setting (access to childcare, child benefits etc.) depends on their knowledge of German. However, since kindergarten attendance for children ages 4 to 6 is nearly universal and since child benefits (the most important child-related transfer for most families) are a well-known and easy to obtain universal measure, it is likely that not controlling for language introduces only

\footnotetext{
${ }^{26} \mathrm{We}$ acknowledge that the same is to some extent true for education. As a first step of the analysis, we therefore also report results from models with no controls at all.
} 
a small bias.

A second issue concerns the women's age at migration. We are interested in isolating the pure effect that results from the women's exposure to the fertility rates in their countries of origin. This suggests that women who arrived as children ("generation 1.5") should not be grouped with the first but rather the second generation, as their first-hand exposure to the fertility rates in the countries of origin is limited. For them, the influence of the exposure effect is more likely to be indirect, via the cultural transmission by the parents, and hence akin to that of the second generation. Our cut-off point separating the first generation from "generation 1.5 " is at age 15 . The results are robust when we use cut-off points at ages 6 or 12 .

Moreover, it is important for the validity of the epidemiological approach in the first generation to also set an upper limit for age at migration. Including all immigrant women regardless of their age at arrival would not be consistent with the empirical strategy. Some of these women arrived in their 40s and a few even in their 50s or later. Consequently, they spent most or all of their fertile years outside Germany and were exposed to both the culture and the institutions of their countries of origin, making it difficult to convincingly disentangle the two influences. Moreover, immigrants from countries and years with high fertility rates are more likely to have had children before migrating. Figure 2 shows that fertility rates among (very) young women are far from being negligible in our sample of origin countries. $^{27}$

Unfortunately, we cannot convincingly control for whether the women already had children on arriving in Germany, as the Mikrozensus only has information on the age of those children who are still living in the household in 2008. Worse, for children over the age of 18, only the two categories "under 27 " and "over 27 " are available. To mitigate concerns about children having been born prior to migration, we therefore set an upper limit of

\footnotetext{
${ }^{27}$ We could only find data on age-specific fertility rates for selected countries and going back to at most 1970 (1975 in the case of Spain). Births at a young age were probably even more frequent in earlier years and for some of the countries that are not included in the figure, such as Turkey.
} 
18 years for age at migration in our main specification. In addition, we control for age at migration to adjust for the fact that even with a relatively narrow age-at-arrival span of 15 to 18 , the women spent different fractions of their reproductive years in Germany. ${ }^{28}$ As a robustness check, we vary the upper age limit from 15 to 25, the limit chosen by Adsera and Ferrer (2011). We also try an age limit of 40. In our view, such a limit is not consistent with the empirical strategy of the epidemiological approach, but may be unavoidable in smaller data sets. By comparing the results with those for a narrower age bracket, we can find out whether controlling for age at migration is sufficient for eliminating the bias.

A final point about the interpretation of the results for the first generation concerns the issue of selection. The epidemiological approach neither allows nor attempts to draw inference about fertility norms in the countries of origin from the behaviour of immigrants in Germany. Both the initial and the return migration decisions are selective, and the group of immigrants and their descendants who we observe in Germany in 2008 is therefore neither a random sample of people in the countries of origin in 2008 nor of the immigrants who originally came to Germany.

Concerns about selection, age of arrival and number of children in the origin country play a much smaller role or no role at all for the second generation of immigrants. ${ }^{29}$ These women were born in Germany and have spent all of their fertile years in the same institutional setting. Moreover, disruptions due to migration do not matter for them, and the variation in language skills is smaller than for the first generation. At the same time, influences from the country of origin will be weaker. Comparing results for the different generations of immigrants therefore provides suggestive evidence about the strength of cultural transmission versus assimilation to the common host country norms.

\footnotetext{
${ }^{28}$ We do not observe how many years the women actually spent in Germany between the year of their arrival and the interview year in 2008. We assume that the length of time spent in the country of origin or elsewhere is independent of country of origin and year of migration.

${ }^{29}$ For the women in generation 1.5 , i.e. those women who immigrated before the age of 15 , the issue of children in the country of origin cannot be ruled out but seems to play only a negligible role. In our sample, there is not a single woman who already has children at age 15 .
} 
The main drawback of estimating the model for the second generation is the smaller sample size. This has two consequences for the identification strategy. First, when estimating the model on the sample of second-generation women aged 45 and above, the number of observations per country becomes so small that using only the within-country variation leads to highly imprecise estimates. Conceptually, defining the appropriate dimension of within-country variation is also less straightforward than for the first generation where year of arrival is a natural choice. For the second generation, it is arguably the fertility norms of their parents' generation that are relevant as cultural transmission mainly operates through this channel. Unfortunately, information on the parents' year of arrival is not available in the Mikrozensus. We use information from the year of birth of secondgeneration women instead. We also tried specifications with proxies from fixed years in the past as in Fernández and Fogli (2009) and from the year of the survey, as in Gevrek et al. (2011). In these cases, all variation is cross-sectional.

The second consequence of the smaller sample size in the second generation concerns the dependent variable. As one way to increase the sample size, we include all women aged 15 and above in our model for the number of children. In this case, we can only estimate the effect of home country fertility rates on the current number of children, and have to be careful to control for the considerable age differences by country of origin (cf. Section $2)$.

\section{Results}

\subsection{First generation}

Table 1 presents our results for the estimation of Equation (1) on the sample of firstgeneration immigrant women who arrived between the ages of 15 and 18 and who are at least 45 years old in the survey year 2008. The first column shows the regression coefficients for the bivariate model. The higher the total fertility rate (TFR) in the 
country of origin in the year of migration, the higher the average completed fertility of immigrant women in Germany. A difference of one child in country-of-origin TFR translates into a difference of about 0.37 children per woman.

The influence of fertility rates in the country of origin on own fertility becomes slightly weaker when compositional differences with respect to age and education (column 2) as well as age at migration (column 3) are controlled for. The specification also contains dummies for the federal states, which capture differences in the access to childcare. The coefficients on education have the expected sign: women with higher education tend to have fewer children.

Our preferred specification for the first generation is the one in which we only exploit the variation within countries of origin. In the relatively small sample of women who arrived up to the age of 18 , the coefficient on TFR increases to 0.98 (1.02 without controlling for age at migration), but has a large standard error attached to it. Interestingly, the coefficients on the education variables are reduced in absolute size in the within-country specification.

Table 2 reports results from the main specification when the upper age limit is varied between 15 and 25. The table also includes results for an upper age limit of 40. Only the coefficients on the TFR are shown. As expected, the sample size and the precision of the estimates increase considerably as the upper age limit becomes less strict.

In our view, four main lessons emerge from the table. First, controlling for age at migration has a negligible effect in the pooled model for most age limits but becomes important in the within model which, by virtue of eliminating time-constant unobserved effects, represents our preferred specification. Second, controlling for age at migration becomes more important when the age limit is less strict. With an age limit of 40 - that is, when even women who spent their entire fertile years abroad are included in the sample - the difference in the point estimates is equal to 0.05 in the pooled model and 0.30 in the within model. Third, the within models lead to larger point estimates than the pooled model. 
Finally, the point estimates in the within models are highly sensitive to the upper limit for age at migration. This sensitivity of the results with respect to the sample definition was masked in previous studies as these relied exclusively on estimates from pooled specifications.

To put the point estimates into perspective, immigrant women in Germany who arrived between the ages of 15 and 18 have on average 2.3 children; the mean is slightly higher for the women who came at a younger age, and is lower for women who arrived when they were older. The total fertility rate by country of origin and year of arrival varies between 1.25 and 6.10 , with a standard deviation of about 1 . According to the point estimates from the within-country models in the last column, a change in the TFR of one unit (which is roughly one standard deviation) is associated with a change in completed fertility of between 0.32 to 1.10 children per immigrant woman in Germany, depending on the upper age limit. ${ }^{30}$ This is between $14 \%$ and $47 \%$ of the average number of children and points to a sizeable impact of the exposure to the country-of-origin fertility rate.

\subsection{Generations 1.5 and 2}

Table 3 summarises the estimation results for generations 1.5 and 2 in the pooled model. The positive effect of fertility rates in the country of ancestry is confirmed in all three samples. However, in the strictest specification in which we consider completed fertility of women aged 45 or above, the sample size becomes fairly small for the second generation, and the coefficient on TFR, while still positive, is estimated only imprecisely (column 1). In column 2 we include all women of the second generation aged 15 and above, the earliest age for which information on the number of children is available in the Mikrozensus. Consequently, we no longer model the influence of TFR on completed fertility but on fertility up to the present age. Although this approach does not allow isolating the effect on total number of births from pure timing effects, it is quite common in the literature

\footnotetext{
${ }^{30}$ We consider only the statistically significant estimates.
} 
and was used by Blau et al. (2013) and Fernández and Fogli (2006; 2009), among others. Like them, we condition on age and age squared to take into account that, other things equal, the number of children increases with age, but in a non-linear fashion. We again find a positive and statistically significant effect of country-of-origin TFR on the number of children of second-generation women in Germany. A TFR that is higher by one child per woman in the country of ancestry translates into an increase in the conditional mean of 0.06 children per woman in Germany.

In the third column, we return to the lower age limit of 45 (and hence to a model of completed fertility) but include those women who immigrated before the age of 15 . These women make up "generation 1.5" and, although born abroad, were excluded from the models for the first generation. When including them with the second generation, the coefficient on TFR is 0.15 and highly statistically significant.

Taken together, the results for the pooled model in the different samples - 1st generation, 2nd generation and generation 1.5, 2nd generation only-show that the effect of fertility rates in the country of origin is strongest for the first generation. The effect persists for the subsequent generations and remains statistically significant throughout most specifications, but becomes weaker. Thus, cultural transmission does occur but is far from complete.

The within-country models summarised in Table 4 confirm a positive influence of countryof-origin TFR on own fertility. As in the first generation, the coefficients are larger than in the pooled models. In contrast, the ranking of the three samples is reversed compared to the pooled model for the second generation: we find the largest point estimate for the very small sample of second-generation women aged 45 and above, and the smallest point estimate for the combined sample of generations 1.5 and 2. However, the standard errors are quite large in the second generation, and only one of the three point estimates is significantly different from zero. 


\subsection{Alternative specifications}

The finding of a positive coefficient on home country TFR is robust to the functional form of the estimation model-Tobit and Poisson models yield the same qualitative results. ${ }^{31}$ The Poisson model for the first generation allows a direct comparison with the study by Cygan-Rehm $(2011,31)$. She finds a coefficient of 0.08 (std. error: 0.03), while our estimate is 0.14 (std. error: 0.02). However, the comparison is at best suggestive since neither the set of conditioning variables nor the population of women considered are exactly the same. When we limit ourselves to the within variation (which Cygan-Rehm does not do), the point estimate in the Poisson model equals 0.43 (std. error: 0.13).

As noted before, we tried different cut-off ages to distinguish between generations 1 and 1.5. When we reduce the cut-off age from 15 to 12 , the coefficients for the first generation in the main specification (with an upper limit of 18 years) are reduced to 0.31 (pooled model) and 0.65 (within-country model). This is in line with the "socialisation hypothesis" already mentioned: the more time the immigrants spent in their countries of origin, the stronger the effect of fertility rates there. At the same time, the precision of the estimate increases due to the larger sample size. With an even lower cut-off age of 6 years, the effect is further reduced to 0.30 (pooled) and 0.31 (within). However, in our main sample with a lower age limit of 45 for completed fertility, the coefficient is no longer statistically significant in the within model.

Yearly information on TFR is available for all countries only from 1960 onwards. For the 1950s, we use data from another source that only reports averages over the periods 1950-1955 and 1956-1960. To make sure that this interpolation does not drive the results, we restrict the sample to women who arrived in 1960 or later. The results change only slightly since, in any case, few women in our sample already migrated in the 1950s.

When we exclude women from Turkey, the most important country of origin and the

\footnotetext{
${ }^{31}$ Only selected results of the following robustness checks are documented in the Appendix. Full results are available from the authors upon request.
} 
country with the largest level and the largest variation in TFR, the coefficient for the first generation becomes smaller in the pooled model (0.22 instead of 0.34 ) but remains almost unchanged at 0.98 in the within model. Excluding Poland and the former Soviet Union (as many immigrants from there may be considered as "ethnic Germans") or keeping only countries with at least 100 observations (first generation) or 15 observations (second generation) has almost no influence on the estimates.

\subsection{Possible mechanisms}

When we decompose the fertility outcome into an extensive and intensive margin, we find that, in the first generation, home country TFR is strongly associated with the number of children in the subsample of women who gave birth to at least one child. On the extensive margin, the results are less clear-cut. When using the entire variation across countries and across time, we find that home country TFR is positively related to the probability of having at least one child. However, the coefficient becomes smaller and statistically insignificant when only the within-country variation is used.

We tentatively conclude from these results that home country TFR exerts a stronger effect on the intensive margin where the variation over time and across countries is greater. The weaker effect on the extensive margin is plausible as the percentage of women with children is high among immigrant women from the countries considered here and varies less across time than the average number of children. Based on data from the SOEP, Milewski $(2007,887)$ similarly finds that "[t]he country of origin does not explain much of the first-birth behaviour of immigrants in West Germany. However, since a first child can be seen as the norm in the countries of origin of the women analysed in this paper and country differences occur mainly in higher parities, further research should study the transition to sub-sequent births as well". Interestingly, we find that in the second generation, for which the share of childless women is higher, the effect works more strongly on the extensive margin than in the first generation. 
As another step towards an analysis of the mechanisms behind the positive relationship, we interact the coefficient on the total fertility rate with the education level (see Tables A.10-A.13 in the Appendix). We find that the relationship tends to be strongest for women with low levels of education. This holds in both the pooled model and the withincountry model. The heterogeneity with respect to education is even more pronounced in the second generation. A related result was obtained by Adsera and Ferrer (2011), who also find that the effect of age at migration on fertility assimilation in Canada is strongest for women with low education.

We also estimated the model separately for women who have a partner at the time of the survey. As Table A.14 shows, the effect of the total fertility rate experienced prior to migration is stronger for women with a partner from the same country of origin. This is consistent with a mutual reinforcement of cultural beliefs, but should be interpreted carefully as women who are particularly attached to their cultural background are more likely to live with a partner from the same country of origin. When we further restrict the sample to those women with a partner from a different origin, we find that a partner with German origin reduces the coefficient on TFR more strongly than a partner from a different foreign background. However, the sample size is very small in this case and the interaction effect is not statistically significant. The same patterns are found in the second generation (Tables A.15-A.17); of course, the caveat about endogenous partner choice applies here as well.

For the second generation we can also distinguish whether only one or both parents have a foreign background and, in the latter case, if they are from the same country. Unfortunately though, the Mikrozensus does not provide this information for all members of the second generation (see the discussion in Section 2 above). Information on parental background is only available if respondents still live with their parents or if they are part of the subsample of the Mikrozensus that contains more detailed questions about immigration. As a result, we can examine the influence of mixed parental origin only for the largest sample of the second generation, that is, for all respondents aged 15 and 
above. $^{32}$ We find that the coefficient on the total fertility rate in the country of origin remains in the same range as in the main specification and that, quite plausibly, the coefficient is strongest if both parents are from the same country of origin (cf. Table A.18). If only one parent is from abroad, the point estimate suggests that the origin of the mother has a slightly stronger influence, but the difference is not statistically significant.

Our main specification contains only a small set of conditioning variables. This is partly due to the nature of the data set: participation in the Mikrozensus is mandatory, but the number of questions is relatively limited. A second reason for not including more variables is the issue of over-controlling. We consider that marital status, labour force participation, foreign nationality and household income all lie on the causal pathway from country-of-origin culture to fertility outcomes. Since we are interested in the total effect of culture, we choose not to condition on them in our main specification. ${ }^{33}$

When we do include them, we find that in the pooled model the coefficient on total fertility rate hardly changes (see Table A.19 in the Appendix). The results for the additional covariates show a plausible pattern. Women who are married tend to have more children; the same is true for women with foreign nationality. Women who work tend to have fewer children, whereas a higher household net income is associated with more children. ${ }^{34}$ When controlling for GDP per capita (in constant 2000 US dollars), the coefficient on the fertility rate increases slightly in the pooled model. The sample size is considerably reduced in this case, as comparable GDP data (we use the World Bank's World Development Indicators) are only available from 1960s and, in the case of Poland, Russia, and Yugoslavia, from 1989/1990 onwards. Including dummies for the decade of arrival to capture the general downward trend in total fertility rates leaves the coefficient on TFR almost unchanged in the pooled model (here, we return to the larger sample by omitting GDP per capita

\footnotetext{
${ }^{32}$ In this sample, in $74 \%$ of all cases both parents are from the same foreign country, while for $11 \%$ of the sample only the mother and for $16 \%$ of the sample only the father has an immigrant background.

${ }^{33}$ Adsera and Ferrer (2011) and Blau et al. (2013, 410) make the same argument.

${ }^{34}$ The answer to the question about household income is voluntary. Item non-response is therefore higher and the sample size is slightly reduced.
} 
again).

In the models with country-of-origin fixed effects (Table A.20), controlling for marital status reduces the coefficient on TFR, while controlling for employment status and household income has only a small effect. Adding dummies for the decade of arrival slightly increases the coefficient, and controlling for GDP per capita has a much larger effect in the within model than in the pooled specification. The coefficient on TFR is reduced to 0.27 and is no longer significantly different from zero. As noted, the loss in statistical power is partly due to the much smaller sample size. Moreover, the negative correlation between TFR and GDP per capita is in many cases even stronger within than across countries.

In our three samples for the second generation, including additional control variables (Tables A.21-A.26 in the Appendix) generally leaves the coefficient on total fertility rate in the same range as in the main specifications of Table 3 and $4 .{ }^{35}$

\subsection{Other measures for fertility in the country of origin}

For comparison with earlier studies which use cross-sectional variation only (e.g., Fernández and Fogli, 2006; 2009; Gevrek et al., 2011), we estimated the model using the TFR from single years, irrespective of the year of migration (see Tables A.27-A.30 in the Appendix). The results for the cross-sectional models are relatively close to the pooled models when single TFR values from 1950, 1960, 1970 or 1980 are used. (As seen above, though, the pooled models underestimate the effect found in the within-country models) In contrast, when the values of 1990 or the survey year 2008 are used, the coefficient increases in the cross-sectional models and deviates considerably from the results for the pooled specification. This is due to the relatively small TFR differences across countries in later years, which are then used to "explain" fertility differences among immigrant groups that arrived earlier, at a time when fertility differences were much greater. Simi-

\footnotetext{
${ }^{35}$ For these three samples, we do not include controls for the decade of arrival as, with the exception of generation 1.5, all women were born in Germany.
} 
lar, though less extreme, dependence on the year chosen for the cross-sectional measure arises in the models for the three samples of the second generation. This sensitivity analysis suggests that choosing the year of measurement for the country of origin influences is far from innocuous.

When country averages for fertility norms from the 1990 wave of the World Values Survey are used as cultural proxies (in separate models), the coefficients on three of the four variables are statistically insignificant. ${ }^{36}$ A higher ideal number of children as reported in the WVS and, in the estimation for the second generation, the belief that children are important for a successful marriage are actually associated with a lower number of children among immigrant women in Germany (cf. Tables A.31 and A.32 in the Appendix). ${ }^{37}$ Admittedly, we do not have a full explanation for these results. After all, the variables from the WVS are arguably a more direct measure of culture than either the total fertility rates or cohort fertility rates. We suspect that the instable relationships found for the WVS variables are partly due to their measurement in 1990, years after most of the immigrant women in our sample arrived in Germany and years after the women of the second generation included in our estimation were born. As already noted in Section 2, fertility norms in Turkey, the country where most of the women in our sample came from, were quite low in 1990 and probably reflected the rapid decline in fertility rather than the high level of these rates that prevailed at the time when many of the immigrant women left Turkey for Germany. However, it seems unlikely that it is only the measurement in a single, late and somewhat arbitrary year that explains the insignificant coefficients - after all, when we used the total fertility rate from 1990 as a proxy for culture, the coefficient remained positive and highly significant. Another explanation could therefore be that it is indeed observed fertility behaviour and not fertility norms as reported in a survey such as the WVS that influences people's own fertility decisions.

\footnotetext{
${ }^{36}$ As noted above, not all countries from the main specification participated in the 1990 wave of the WVS. In Turkey, only two of the four questions were part of the survey. The sample size is therefore smaller than in the main specification.

${ }^{37}$ For the second generation, results are shown only for one of the three samples. In the other two samples, all coefficients on the WVS variables are statistically insignificant.
} 
Finally, we replaced total fertility rates in the year of migration by completed cohort fertility rates for people who were born in the same year but who stayed in the country of origin. These cohort fertility rates are positively related with completed fertility of immigrants in Germany (Table A.33). In the pooled model, the relationship is stronger than for the total fertility rate (0.52 versus 0.34$)$. In the within model, the coefficients are virtually identical regardless of which measure for country of origin fertility is used, but the coefficient on cohort fertility is less precisely estimated as cohort fertility rates are not available for all countries and rely on linear interpolation between three or, in the case of Turkey, two data points. Nevertheless, we believe that these novel results concerning the influence of cohort fertility rates in the country of origin are a useful complement to the findings based on total fertility rates that have so far been employed in the literature. For the second generation (which was born in Germany), people of the same age in the country of origin seem to be less important as a reference group, but the small sample size and the fact that the cohort fertility measure varies even less than in the first generation (as the variation in the year of birth is smaller) make it difficult to generalise the results beyond our sample (cf. Tables A.34-A.36).

\section{Conclusion}

In this paper we have studied the fertility outcomes of first- and second-generation immigrants in Germany using data from the 2008 wave of the Mikrozensus, a representative $1 \%$ sample of the German population. We show that total fertility rates and completed fertility rates in the country of origin have a sizeable and statistically significant impact on completed fertility rates in Germany. The findings for completed fertility rates are novel: previous studies have only used the more widely available total fertility rates. Since the women all live under roughly the same institutional framework in Germany, our results suggest that country-of-origin influences matter for fertility outcomes.

The results are robust to controlling for compositional differences between women from 
different countries and cohorts. Moreover, the positive effect of fertility rates survives when country of origin fixed effects are allowed for, mitigating concerns about omitted variables. The effect becomes slightly larger in this case and is more sensitive to the choice of the upper limit for age at migration as well as to the control for age at migration. The difference between pooled and within specifications and the importance of controlling for age at migration have not been studied in the literature before.

We find that the influence of country of origin fertility rates is strongest for the immigrant generation itself, that is, for women who were born and socialised in the country of origin. The effect persists into the second generation but becomes smaller. This suggests that parents vertically transmit the culture of their country of origin, but that horizontal and oblique influences in the host country play a role as well (see the survey by Bisin and Verdier, 2011). Quite plausibly, the influence is strongest for women with a partner from the same country of origin and, for women from the second generation, if both parents are from the same origin. As partner choice is endogenous, the first result should be considered as descriptive, however.

Taken together, these results suggest that cultural or country-of-origin influences should be taken into account in the evaluation of the effectiveness of policy measures aiming at the increase of fertility rates, or when comparing specific policy measures across countries. In the short run, monetary incentives and institutional settings alone may not induce a shift in fertility behaviour to the expected extent or not as quickly as hoped for.

In future research, the precise workings of the cultural influence and of the transmission mechanisms should be studied in greater detail. The literature has already established that in the US the number of own siblings (Fernández and Fogli, 2006) and own labour market experience prior to migration (Blau and Kahn, 2011) can explain part but not all of the association between country of origin culture and own fertility or labour market outcomes. For first-generation immigrants in Germany, Cygan-Rehm (2011) confirms the influence of the number of own siblings but shows that the cultural effect is still present 
after controlling for this variable. For second-generation immigrants in Germany, these questions have not yet been investigated. The difficulty is that social science surveys such as SOEP include the necessary questions but have a relatively limited number of observations for the second generation, while the Mikrozensus provides a large sample with a smaller set of covariates.

Nevertheless, the Mikrozensus-based analysis in the present paper allows establishing some first results concerning the mechanisms behind the cultural influence on fertility. We find that the cultural influence is stronger on the intensive margin than on the decision to have at least one child. We also show that the cultural influence is strongest for women with low levels of education and, especially in the second generation, almost disappears for women with tertiary education. In the literature that directly focuses on the fertility effects of country of origin variables, this is a novel finding. A similar interaction effect with education was found by Adsera and Ferrer (2011), who study the effects of age at migration on fertility assimilation in Canada. We also find that there is no robust relationship between completed fertility of immigrants in Germany and direct measures of fertility norms from the World Values Survey 1990, hence years after most immigrant women in our sample left their country. This suggests that the socialisation up to the year of migration and one's own birth cohort exert a stronger influence than the later evolution in one's country of origin. The result may also suggest that observed fertility outcomes are a stronger reference point for one's own behaviour than norms and attitudes.

\section{References}

Adsera, A. and A. Ferrer (2011). Age at migration, language and fertility patterns among migrants to Canada. Discussion Paper 5552, IZA, Bonn.

Algan, Y. and P. Cahuc (2010). Inherited trust and growth. American Economic Review 100(5), 2060-2092. 
Avitabile, C., I. Clots-Figueras, and P. Masella (2012). Citizenship, fertility and parental investment. Working Paper 305, CSEF, Department of Economics, University of Naples.

Basten, C. C. and F. Betz (2012). Beyond work ethic: Religion, individual and political preferences. American Economic Journal: Economic Policy, forthcoming.

Bisin, A. and T. Verdier (2011). The economics of cultural transmission and socialization. In J. Benhabib, M. O. Jackson, and A. Bisin (Eds.), Handbook of Social Economics, Volume 1A. San Diego; Amsterdam: North.

Blau, F. D. and L. M. Kahn (2011). Substitution between individual and cultural capital: Pre-migration labor supply, culture and US labor market outcomes among immigrant women. NBER Working Paper 17275, Cambridge, MA.

Blau, F. D., L. M. Kahn, A. Y.-H. Liu, and K. L. Papps (2013). The transmission of women's fertility, human capital, and work orientation across immigrant generations. Journal of Population Economics 26(2), 405-435.

Blau, F. D., L. M. Kahn, and K. L. Papps (2011). Gender, source country characteristics and labor market assimilation among immigrants: 1980-2000. Review of Economics and Statistics 93(1), 43-58.

Cygan-Rehm, K. (2011). Between here and there: immigrant fertility patterns in Germany. BGPE Discussion Paper No. 109, Friedrich-Alexander-University ErlangenNuremberg.

Eugster, B., R. Lalive, A. Steinhauer, and J. Zweimüller (2011). The demand for social insurance: does culture matter? Economic Journal 121, F413-F448.

Fernández, R. (2007). Women, work, and culture (Alfred Marshall Lecture). Journal of the European Economic Association 5(2-3), 305-332. 
Fernández, R. (2008). Culture and economics. In S. N. Durlauf and L. E. Blume (Eds.), The New Palgrave Dictionary of Economics (2nd ed.). Basingstoke, Hampshire ; New York: Palgrave Macmillan.

Fernández, R. (2011). Does culture matter? In J. Benhabib, M. O. Jackson, and A. Bisin (Eds.), Handbook of Social Economics, Volume 1A. San Diego; Amsterdam: NorthHolland.

Fernández, R. and A. Fogli (2006). Fertility: The role of culture and family experience. Journal of the European Economic Association 4(2-3), 552-561.

Fernández, R. and A. Fogli (2009). Culture: An empirical investigation of beliefs, work, and fertility. American Economic Journal: Macroeconomics 1(1), 146-177.

Furtado, D., M. Marcén, and A. Sevilla-Sanz (2013). Does culture affect divorce decisions? Evidence from European immigrants in the US. Demography, forthcoming.

Gevrek, Z. E., D. Gevrek, and S. Gupta (2011). Culture, intermarriage, and differentials in second-generation immigrant women's labor supply. Discussion Paper 6043, IZA, Bonn.

Guiso, L., P. Sapienza, and L. Zingales (2006). Does culture affect economic outcomes? Journal of Economic Perspectives 20(2), 23-48.

Hacettepe University Institute of Population Studies (1999). Turkey Demographic and Health Survey 1998. Ankara.

Hacettepe University Institute of Population Studies (2009). Turkey Demographic and Health Survey 2008. Ankara.

Henrich, J., R. Boyd, S. Bowles, C. Camerer, E. Fehr, H. Gintis, and R. McElreath (2001). In search of Homo Economicus: behavioral experiments in 15 small-scale societies. American Economic Review Papers and Proceedings 91, 73-78. 
Kok, S., N. Bosch, A. Deelen, and R. Euwals (2011). Migrant women on the labour market: On the role of home- and host-country participation. Discussion Paper 180, CPB Netherlands Bureau for Economic Policy Analysis, The Hague.

Kreyenfeld, M., K. Zeman, M. Burkimsher, and I. Jaschinski (2011). Fertility data for German-speaking countries: What is the potential? What are the pitfalls? MPIDR Working Paper 2011-003, Max Planck Institute for Demographic Research, Rostock.

Luthra, R. R. (2010a). Assimilation in a new context: Educational attainment of the immigrant second generation in Germany. Working Paper 2010-21, ISER Institute for Social and Economic Research, University of Essex.

Luthra, R. R. (2010b). Enduring inequality: Labour market outcomes of the immigrant second generation in Germany. Working Paper 2010-30, ISER Institute for Social and Economic Research, University of Essex.

Luttmer, E. F. P. and M. Singhal (2011). Culture, context, and the taste for redistribution. American Economic Journal: Economic Policy 3, 157-179.

Milewski, N. (2007). First child of immigrant workers and their descendants in West Germany: interrelation of events, disruption, or adaptation? Demographic Research 17, 859-896.

Myrskylä, M., J. R. Goldstein, and Y.-H. A. Cheng (2012). New cohort fertility forecasts for the developed world. MPIDR Working Paper 2012-014, Max Planck Institute for Demographic Research, Rostock.

Pötzsch, O. (2010). Cohort fertility: A comparison of the results of the official birth statistics and of the Microcensus survey 2008. Comparative Population Studies - Zeitschrift für Bevölkerungswissenschaft 35(1), 185-204. 
Riphahn, R. T. (2003). Cohort effects in the educational attainment of second generation immigrants in Germany: An analysis of census data. Journal of Population Economics 16(4), 711-737.

Riphahn, R. T. (2005). Are there diverging time trends in the educational attainment of nationals and second generation immigrants? Journal of Economics and Statistics Jahrbücher für Nationalökonomie und Statistik 225, 325-346.

Sajons, C. (2011a). Does granting citizenship to immigrant children affect family return migration? Unpublished working paper, Universitat Pompeu Fabra, Barcelona.

Sajons, C. (2011b). Does immigrants' integration behavior change when their children are born with the host-country citizenship? Unpublished working paper, Universitat Pompeu Fabra, Barcelona.

Steinhauer, A. (2012). Gender identity and culture: The effect of mother's guilt on fertility and female labor supply in Switzerland. Unpublished working paper, University of Zurich.

United Nations Population Division (2011). World Population Prospects: The 2010 Revision, CD Rom edition. http://esa.un.org/wpp/unpp/panel_population.htm. Accessed on 7 December 2012.

World Bank (2012). World Development Indicators. http://data.worldbank.org/ data-catalog/world-development-indicators. Accessed on 7 December 2012. 
Tables

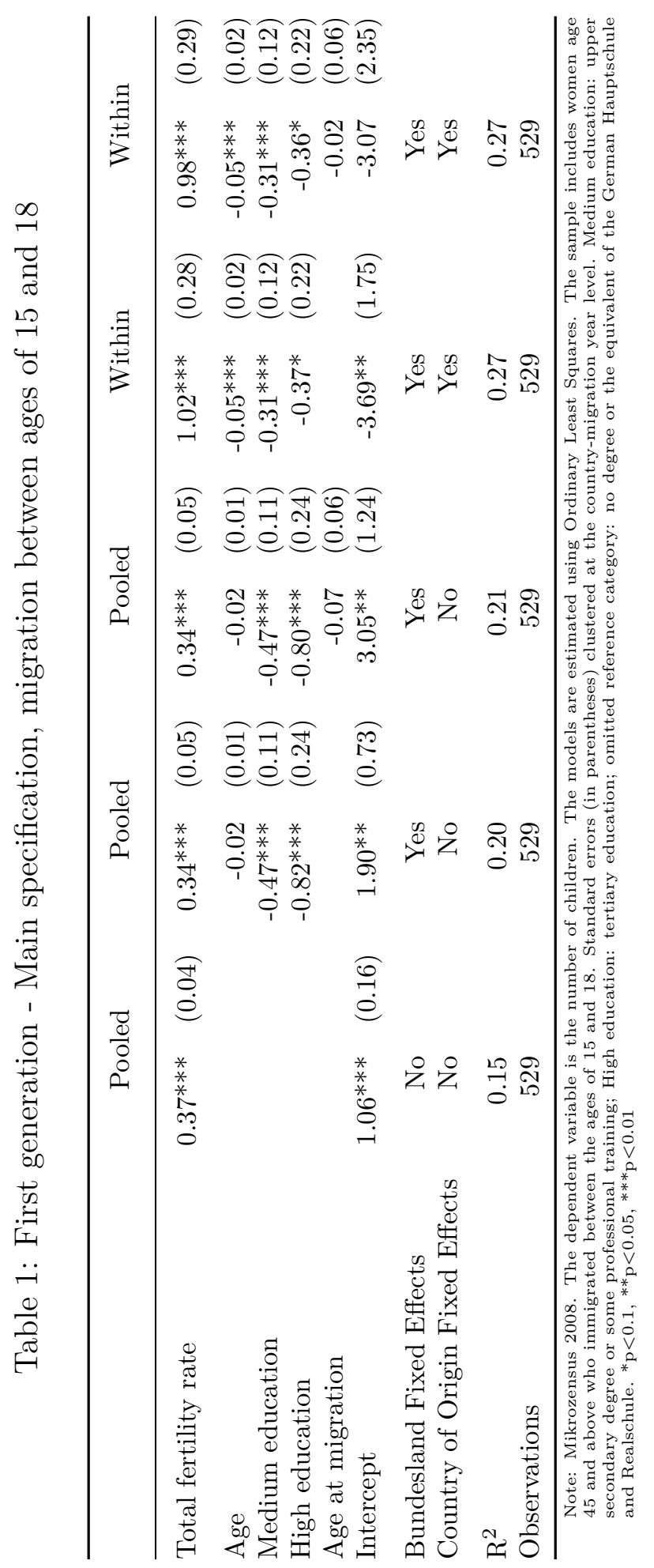


Table 2: First generation - Main specification, different upper limits for age at migration

\begin{tabular}{|c|c|c|c|c|c|c|}
\hline \multirow[b]{2}{*}{ Age limit } & \multirow[b]{2}{*}{$\mathrm{N}$} & \multirow[b]{2}{*}{ No controls } & \multicolumn{2}{|l|}{ Pooled } & \multicolumn{2}{|c|}{ Within } \\
\hline & & & $\mathrm{w} / \mathrm{o}$ age at $\mathrm{m}$. & $\mathrm{w} /$ age at $\mathrm{m}$. & $\mathrm{w} / \mathrm{o}$ age at $\mathrm{m}$. & $\mathrm{w} /$ age at $\mathrm{m}$. \\
\hline \multirow[t]{2}{*}{15} & 76 & $0.34^{* * *}$ & 0.20 & 0.20 & 0.07 & 0.07 \\
\hline & & $(0.13)$ & $(0.14)$ & $(0.14)$ & $(0.74)$ & $(0.74)$ \\
\hline \multirow[t]{2}{*}{16} & 186 & $0.38^{* * *}$ & $0.32^{* * *}$ & $0.32^{* * *}$ & 0.86 & 0.80 \\
\hline & & $(0.09)$ & $(0.10)$ & $(0.10)$ & $(0.57)$ & $(0.62)$ \\
\hline \multirow[t]{2}{*}{17} & 319 & $0.43^{* * *}$ & $0.36^{* * *}$ & $0.35 * * *$ & $1.32 * * *$ & $1.10^{* *}$ \\
\hline & & $(0.07)$ & $(0.08)$ & $(0.08)$ & $(0.44)$ & $(0.48)$ \\
\hline \multirow[t]{2}{*}{18} & 529 & $0.37^{* * *}$ & $0.34^{* * *}$ & $0.34^{* * *}$ & $1.02^{* * *}$ & $0.98^{* * *}$ \\
\hline & & $(0.04)$ & $(0.05)$ & $(0.05)$ & $(0.28)$ & $(0.29)$ \\
\hline \multirow[t]{2}{*}{19} & 743 & $0.34^{* * *}$ & $0.31^{* * *}$ & $0.31^{* * *}$ & $0.74^{* * *}$ & $0.68 * * *$ \\
\hline & & $(0.03)$ & $(0.04)$ & $(0.04)$ & $(0.24)$ & $(0.24)$ \\
\hline \multirow[t]{2}{*}{20} & 948 & $0.35^{* * *}$ & $0.31^{* * *}$ & $0.31^{* * *}$ & $0.38^{* *}$ & $0.36^{* *}$ \\
\hline & & $(0.03)$ & $(0.03)$ & $(0.03)$ & $(0.20)$ & $(0.19)$ \\
\hline \multirow[t]{2}{*}{21} & 1126 & $0.35^{* * *}$ & $0.31^{* * *}$ & $0.31^{* * *}$ & $0.35^{* *}$ & $0.39^{* *}$ \\
\hline & & $(0.03)$ & $(0.03)$ & $(0.03)$ & $(0.17)$ & $(0.17)$ \\
\hline \multirow[t]{2}{*}{22} & 1345 & $0.35^{* * *}$ & $0.31^{* * *}$ & $0.31^{* * *}$ & $0.27^{* *}$ & $0.35^{* *}$ \\
\hline & & $(0.03)$ & $(0.03)$ & $(0.03)$ & $(0.14)$ & $(0.15)$ \\
\hline \multirow[t]{2}{*}{23} & 1542 & $0.36^{* * *}$ & $0.31^{* * *}$ & $0.31^{* * *}$ & 0.15 & $0.32^{* *}$ \\
\hline & & $(0.03)$ & $(0.03)$ & $(0.03)$ & $(0.15)$ & $(0.16)$ \\
\hline \multirow[t]{2}{*}{24} & 1750 & $0.36^{* * *}$ & $0.30 * * *$ & $0.30 * * *$ & 0.17 & $0.33^{* *}$ \\
\hline & & $(0.03)$ & $(0.03)$ & $(0.03)$ & $(0.14)$ & $(0.15)$ \\
\hline \multirow[t]{2}{*}{25} & 1931 & $0.35^{* * *}$ & $0.29^{* * *}$ & $0.29 * * *$ & $0.20^{* *}$ & $0.34^{* *}$ \\
\hline & & $(0.03)$ & $(0.03)$ & $(0.03)$ & $(0.11)$ & $(0.13)$ \\
\hline \multirow[t]{2}{*}{40} & 4733 & $0.30 * * *$ & $0.23^{* * *}$ & $0.28^{* * *}$ & $0.11^{* *}$ & $0.41^{* * *}$ \\
\hline & & $(0.03)$ & $(0.02)$ & $(0.03)$ & $(0.06)$ & $(0.07)$ \\
\hline
\end{tabular}

Note: Mikrozensus 2008. The dependent variable is the number of children. The models are estimated using Ordinary Least Squares. Each model includes women age 45 and above who immigrated between the ages of 15 and the upper age limit. The specifications are the same as in Table 1 . 'age at $\mathrm{m} .=$ age at migration'. 'w/ $=$ with'. 'w/o = without'. Standard errors (in parentheses) are clustered at the country-migration year level. ${ }^{*} \mathrm{p}<0.1,{ }^{* *} \mathrm{p}<0.05,{ }^{* * *} \mathrm{p}<0.01$ 
Table 3: Second generation - Main specification for different samples, pooled model

\begin{tabular}{|c|c|c|c|c|c|c|}
\hline \multirow[b]{3}{*}{ Total fertility rate } & \multicolumn{4}{|c|}{ Generation 2} & \multirow{2}{*}{\multicolumn{2}{|c|}{$\begin{array}{c}\text { Generations } 1.5 \text { and } 2 \\
\text { Age } 45+\end{array}$}} \\
\hline & \multicolumn{2}{|c|}{ Age $45+$} & \multicolumn{2}{|c|}{ Age $15+$} & & \\
\hline & 0.03 & $(0.08)$ & $0.06^{* * *}$ & $(0.02)$ & $0.15^{* * *}$ & $(0.03)$ \\
\hline Age & 0.03 & $(0.03)$ & $0.16^{* * *}$ & $(0.02)$ & 0.00 & $(0.01)$ \\
\hline Medium education & $-1.12^{* * *}$ & $(0.40)$ & $-0.40^{* * *}$ & $(0.05)$ & $-0.65^{* * *}$ & $(0.12)$ \\
\hline High education & $-1.67 * * *$ & $(0.37)$ & $-1.02^{* * *}$ & $(0.08)$ & $-1.19^{* * *}$ & $(0.19)$ \\
\hline $\mathrm{Age}^{2}$ & & & $-0.00 * * *$ & $(0.00)$ & & \\
\hline Intercept & -0.80 & $(1.89)$ & $-2.38^{* * *}$ & $(0.23)$ & 1.29 & $(0.97)$ \\
\hline Bundesland Fixed Effects & Yes & & Yes & & Yes & \\
\hline $\mathrm{R}^{2}$ & 0.31 & & 0.44 & & 0.19 & \\
\hline Observations & 93 & & 3532 & & 495 & \\
\hline
\end{tabular}

Table 4: Second generation - Main specification for different samples, within model

\begin{tabular}{|c|c|c|c|c|c|c|}
\hline \multirow[b]{3}{*}{ Total fertility rate } & \multicolumn{4}{|c|}{ Generation 2} & \multirow{2}{*}{\multicolumn{2}{|c|}{$\begin{array}{c}\text { Generations } 1.5 \text { and } 2 \\
\text { Age } 45+\end{array}$}} \\
\hline & \multicolumn{2}{|c|}{ Age $45+$} & \multicolumn{2}{|c|}{ Age $15+$} & & \\
\hline & 0.74 & $(0.99)$ & $0.26^{* * *}$ & $(0.06)$ & 0.17 & $(0.31)$ \\
\hline Age & 0.06 & $(0.04)$ & $0.11^{* * *}$ & $(0.02)$ & 0.00 & $(0.02)$ \\
\hline Medium education & $-1.11^{* *}$ & $(0.50)$ & $-0.38^{* * *}$ & $(0.04)$ & $-0.52^{* * *}$ & $(0.12)$ \\
\hline High education & $-1.58^{* * *}$ & $(0.44)$ & $-1.00^{* * *}$ & $(0.08)$ & $-1.04^{* * *}$ & $(0.22)$ \\
\hline $\operatorname{Age}^{2}$ & & & $-0.00^{* * *}$ & $(0.00)$ & & \\
\hline Intercept & -6.90 & $(6.94)$ & $-3.40^{* * *}$ & $(0.45)$ & 0.52 & $(2.04)$ \\
\hline Bundesland Fixed Effects & Yes & & Yes & & Yes & \\
\hline Country of Origin Fixed Effects & Yes & & Yes & & Yes & \\
\hline $\mathrm{R}^{2}$ & 0.40 & & 0.45 & & 0.25 & \\
\hline Observations & 93 & & 3532 & & 495 & \\
\hline
\end{tabular}




\section{Figures}

Figure 1: Illustration of the empirical strategy

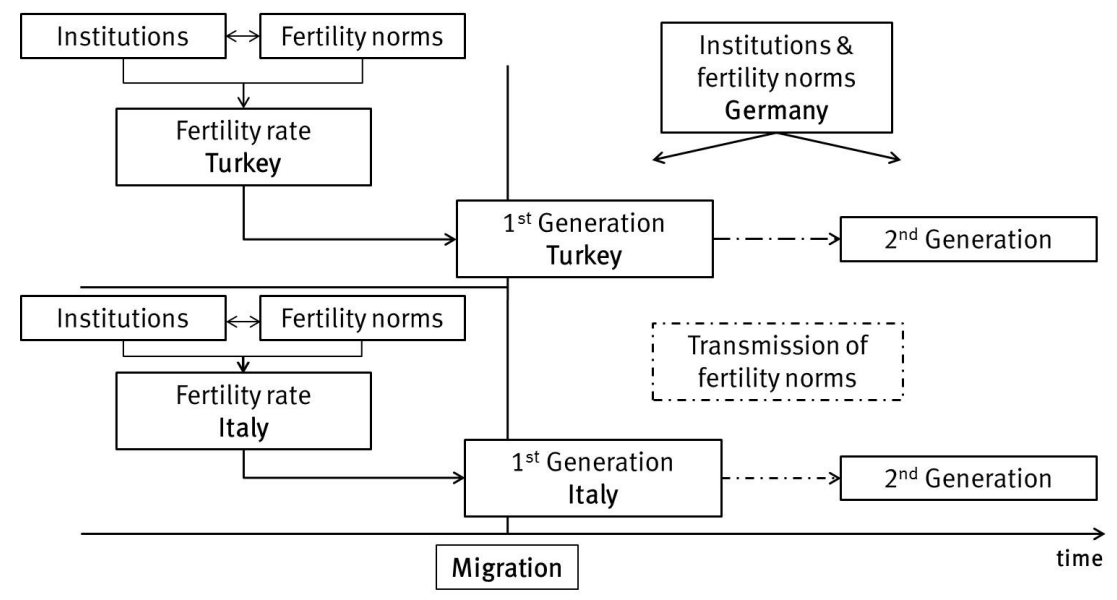

Figure 2: Age-specific fertility rates in 1970

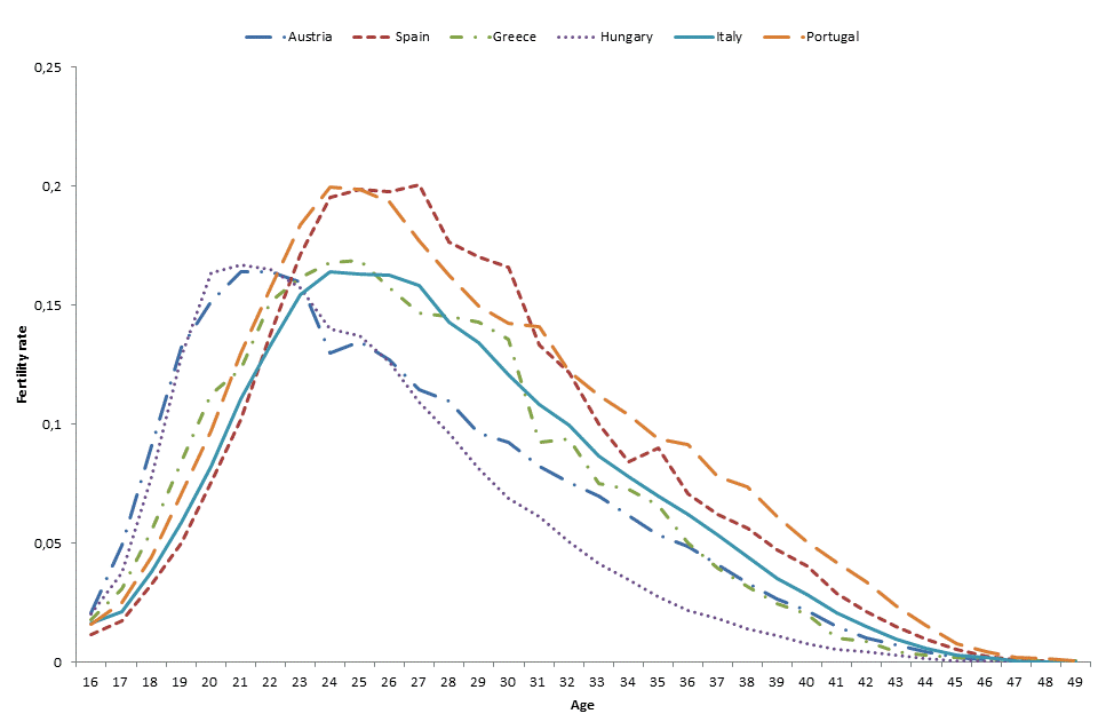

Source: Own representation based on OECD (2013): Age-specific profiles of fertility rates (last update of data: 23 February 2012). Values for 1970, except for Spain (1975). 


\section{A Appendix}

\section{A.1 Summary statistics}

\section{A.1.1 First generation}

Table A.1: First generation, age 45 and above - Number of children

\begin{tabular}{|c|c|c|c|c|}
\hline & $\mathrm{N}$ & $\begin{array}{l}\text { Avg. nb. of } \\
\text { children }\end{array}$ & $\begin{array}{l}\text { Share of women } \\
\text { with children }\end{array}$ & $\begin{array}{l}\text { Avg. nb. of children } \\
\text { (women with children only) }\end{array}$ \\
\hline \multicolumn{5}{|l|}{ Country of origin } \\
\hline Afghanistan & 2 & 2.0 & 1.00 & 2.0 \\
\hline Austria & 40 & 1.3 & 0.78 & 1.7 \\
\hline France & 6 & 1.5 & 0.67 & 2.3 \\
\hline Greece & 26 & 2.1 & 0.96 & 2.2 \\
\hline Hungary & 3 & 1.0 & 0.67 & 1.5 \\
\hline Iran & 2 & 1.5 & 1.00 & 1.5 \\
\hline Iraq & 1 & 0.0 & 0.00 & \\
\hline Italy & 52 & 2.4 & 0.94 & 2.6 \\
\hline Morocco & 6 & 4.3 & 1.00 & 4.3 \\
\hline Poland & 41 & 1.4 & 0.83 & 1.7 \\
\hline Portugal & 8 & 1.9 & 0.88 & 2.1 \\
\hline Soviet Union & 19 & 1.8 & 0.95 & 1.9 \\
\hline Spain & 11 & 2.4 & 1.00 & 2.4 \\
\hline Turkey & 194 & 3.0 & 0.98 & 3.1 \\
\hline Vietnam & 3 & 2.7 & 1.00 & 2.7 \\
\hline Yugoslavia & 115 & 1.9 & 0.89 & 2.2 \\
\hline Total & 529 & 2.3 & 0.92 & 2.5 \\
\hline \multicolumn{5}{|l|}{ Education } \\
\hline Low & 375 & 2.6 & 0.93 & 2.7 \\
\hline Medium & 140 & 1.8 & 0.89 & 2.0 \\
\hline High & 14 & 1.6 & 0.86 & 1.8 \\
\hline Total & 529 & 2.3 & 0.92 & 2.5 \\
\hline \multicolumn{5}{|l|}{ Origin of partner } \\
\hline No partner & 111 & 1.9 & 0.86 & 2.2 \\
\hline Partner with same origin & 329 & 2.7 & 0.97 & 2.8 \\
\hline Partner with different origin & 89 & 1.6 & 0.79 & 2.0 \\
\hline Total & 529 & 2.3 & 0.92 & 2.5 \\
\hline \multicolumn{5}{|l|}{ Citizenship } \\
\hline German & 168 & 2.0 & 0.90 & 2.3 \\
\hline German and foreign & 18 & 2.3 & 0.94 & 2.5 \\
\hline Foreign & 343 & 2.5 & 0.92 & 2.7 \\
\hline Total & 529 & 2.3 & 0.92 & 2.5 \\
\hline
\end{tabular}

Source: Mikrozensus 2008. The sample comprises women who immigrated between the ages of 15 and 20 and who still lived in Germany in 2008. Due to the narrow bracket for age at arrival and to selective return migration, the numbers shown in the table do not necessarily generalize to all immigrant women from the respective countries of origin. 
Table A.2: First generation, age 45 and above - Socio-economic characteristics

\begin{tabular}{|c|c|c|c|c|c|c|c|c|c|c|c|}
\hline & \multirow[b]{2}{*}{$\mathrm{N}$} & \multirow[b]{2}{*}{ Married } & \multicolumn{3}{|c|}{ Education } & \multicolumn{3}{|c|}{ Origin of partner } & \multicolumn{3}{|c|}{ Nationality } \\
\hline & & & Low & Medium & High & None & Same & Different & German & Both & Foreign \\
\hline Afghanistan & 2 & 1.00 & 0.50 & 0.00 & 0.50 & 0.00 & 0.50 & 0.50 & 1.00 & 0.00 & 0.00 \\
\hline Austria & 40 & 0.78 & 0.38 & 0.63 & 0.00 & 0.23 & 0.05 & 0.72 & 0.25 & 0.00 & 0.75 \\
\hline France & 6 & 0.67 & 0.33 & 0.67 & 0.00 & 0.17 & 0.17 & 0.67 & 0.00 & 0.00 & 1.00 \\
\hline Greece & 26 & 0.81 & 0.69 & 0.31 & 0.00 & 0.19 & 0.77 & 0.04 & 0.00 & 0.15 & 0.85 \\
\hline Hungary & 3 & 0.67 & 0.00 & 1.00 & 0.00 & 0.33 & 0.00 & 0.67 & 1.00 & 0.00 & 0.00 \\
\hline Iran & 2 & 1.00 & 0.50 & 0.00 & 0.50 & 0.00 & 1.00 & 0.00 & 0.00 & 0.50 & 0.50 \\
\hline Iraq & 1 & 0.00 & 1.00 & 0.00 & 0.00 & 1.00 & 0.00 & 0.00 & 1.00 & 0.00 & 0.00 \\
\hline Italy & 52 & 0.88 & 0.87 & 0.12 & 0.02 & 0.06 & 0.85 & 0.10 & 0.06 & 0.02 & 0.92 \\
\hline Morocco & 6 & 0.67 & 0.83 & 0.17 & 0.00 & 0.33 & 0.67 & 0.00 & 0.50 & 0.17 & 0.33 \\
\hline Poland & 41 & 0.73 & 0.37 & 0.54 & 0.10 & 0.22 & 0.37 & 0.41 & 0.93 & 0.02 & 0.05 \\
\hline Portugal & 8 & 0.75 & 0.63 & 0.25 & 0.13 & 0.25 & 0.38 & 0.38 & 0.13 & 0.00 & 0.88 \\
\hline Soviet Union & 19 & 0.74 & 0.42 & 0.58 & 0.00 & 0.26 & 0.58 & 0.16 & 0.84 & 0.00 & 0.16 \\
\hline Spain & 11 & 0.73 & 0.91 & 0.09 & 0.00 & 0.36 & 0.36 & 0.27 & 0.18 & 0.09 & 0.73 \\
\hline Turkey & 194 & 0.84 & 0.88 & 0.10 & 0.02 & 0.17 & 0.82 & 0.01 & 0.26 & 0.03 & 0.71 \\
\hline Vietnam & 3 & 0.33 & 1.00 & 0.00 & 0.00 & 0.67 & 0.33 & 0.00 & 0.67 & 0.00 & 0.33 \\
\hline Yugoslavia & 115 & 0.70 & 0.65 & 0.33 & 0.02 & 0.30 & 0.54 & 0.17 & 0.32 & 0.03 & 0.65 \\
\hline Total & 529 & 0.78 & 0.71 & 0.26 & 0.03 & 0.21 & 0.62 & 0.17 & 0.32 & 0.03 & 0.65 \\
\hline
\end{tabular}

Source: Mikrozensus 2008. The sample comprises women who immigrated between the ages of 15 and 20 and who still lived in Germany in 2008 . Due to the narrow bracket for age at arrival and to selective return migration, the numbers shown in the table do not necessarily generalize to all immigran women from the respective countries of origin.

Table A.3: First generation, age 45 and above - Arrival history

\begin{tabular}{|c|c|c|c|c|c|c|c|c|c|c|}
\hline & \multirow[b]{2}{*}{$\mathrm{N}$} & \multicolumn{3}{|c|}{ Years since migration } & \multicolumn{3}{|c|}{ Age at migration } & \multicolumn{3}{|c|}{ Age } \\
\hline & & Mean & Min & Max & Mean & Min & Max & Mean & Min & $\operatorname{Max}$ \\
\hline Afghanistan & 2 & 32.0 & 27 & 37 & 18.0 & 18 & 18 & 50.0 & 45 & 55 \\
\hline Austria & 40 & 41.5 & 29 & 58 & 16.9 & 15 & 18 & 58.4 & 45 & 76 \\
\hline France & 6 & 36.3 & 28 & 45 & 17.2 & 16 & 18 & 53.5 & 45 & 62 \\
\hline Greece & 26 & 37.9 & 27 & 46 & 16.6 & 15 & 18 & 54.5 & 45 & 64 \\
\hline Hungary & 3 & 42.7 & 32 & 52 & 17.7 & 17 & 18 & 60.3 & 50 & 69 \\
\hline Iran & 2 & 34.5 & 30 & 39 & 16.5 & 15 & 18 & 51.0 & 45 & 57 \\
\hline Iraq & 1 & 30.0 & 30 & 30 & 18.0 & 18 & 18 & 48.0 & 48 & 48 \\
\hline Italy & 52 & 37.1 & 27 & 49 & 16.8 & 15 & 18 & 54.0 & 45 & 65 \\
\hline Morocco & 6 & 32.8 & 27 & 46 & 16.5 & 15 & 18 & 49.3 & 45 & 61 \\
\hline Poland & 41 & 36.2 & 27 & 52 & 16.7 & 15 & 18 & 52.9 & 45 & 70 \\
\hline Portugal & 8 & 35.6 & 28 & 50 & 16.6 & 15 & 18 & 52.3 & 45 & 65 \\
\hline Soviet Union & 19 & 35.3 & 29 & 45 & 16.8 & 15 & 18 & 52.1 & 46 & 62 \\
\hline Spain & 11 & 39.1 & 30 & 48 & 17.0 & 15 & 18 & 56.1 & 48 & 63 \\
\hline Turkey & 194 & 33.9 & 27 & 46 & 17.0 & 15 & 18 & 50.9 & 45 & 63 \\
\hline Vietnam & 3 & 29.7 & 29 & 30 & 16.0 & 15 & 18 & 45.7 & 45 & 47 \\
\hline Yugoslavia & 115 & 38.7 & 29 & 56 & 17.0 & 15 & 18 & 55.7 & 45 & 73 \\
\hline Total & 529 & 36.4 & 27 & 58 & 16.9 & 15 & 18 & 53.3 & 45 & 76 \\
\hline
\end{tabular}

Source: Mikrozensus 2008. The sample comprises women who immigrated between the ages of 15 and 20 and who still lived in Germany in 2008. Due to the narrow bracket for age at arrival and to selective return migration, the numbers shown in the table do not necessarily generalize to all immigrant women from the respective countries of origin. 


\section{A.1.2 Second generation}

Table A.4: Second generation, age 15 and above - Number of children

\begin{tabular}{|c|c|c|c|c|}
\hline & $\mathrm{N}$ & $\begin{array}{l}\text { Avg. nb. of } \\
\text { children }\end{array}$ & $\begin{array}{l}\text { Share of women } \\
\text { with children }\end{array}$ & $\begin{array}{c}\text { Avg. nb. of children } \\
\text { (women with children only) }\end{array}$ \\
\hline \multicolumn{5}{|l|}{ Country of origin } \\
\hline Afghanistan & 21 & 0.5 & 0.14 & 3.3 \\
\hline Austria & 117 & 0.5 & 0.26 & 1.9 \\
\hline China & 5 & 0.0 & 0.00 & \\
\hline France & 56 & 0.3 & 0.14 & 1.9 \\
\hline Greece & 181 & 0.6 & 0.32 & 1.8 \\
\hline Hungary & 26 & 0.2 & 0.08 & 2.0 \\
\hline Iran & 42 & 0.2 & 0.17 & 1.1 \\
\hline Iraq & 3 & 1.0 & 0.33 & 3.0 \\
\hline Italy & 459 & 0.6 & 0.34 & 1.8 \\
\hline Morocco & 37 & 0.5 & 0.24 & 2.1 \\
\hline Poland & 294 & 0.1 & 0.04 & 1.7 \\
\hline Portugal & 61 & 0.3 & 0.20 & 1.7 \\
\hline Soviet Union & 150 & 0.2 & 0.15 & 1.3 \\
\hline Spain & 92 & 0.8 & 0.43 & 1.9 \\
\hline Turkey & 1564 & 0.5 & 0.27 & 1.8 \\
\hline United States & 45 & 0.7 & 0.33 & 2.0 \\
\hline Vietnam & 37 & 0.1 & 0.05 & 1.5 \\
\hline Yugoslavia & 342 & 0.5 & 0.31 & 1.8 \\
\hline Total & 3532 & 0.5 & 0.26 & 1.8 \\
\hline \multicolumn{5}{|l|}{ Education } \\
\hline Low & 1981 & 0.3 & 0.16 & 2.1 \\
\hline Medium & 1408 & 0.7 & 0.39 & 1.7 \\
\hline High & 143 & 0.4 & 0.26 & 1.4 \\
\hline Total & 3532 & 0.5 & 0.26 & 1.8 \\
\hline \multicolumn{5}{|l|}{ Origin of partner } \\
\hline No partner & 729 & 0.3 & 0.19 & 1.8 \\
\hline Partner with same origin & 1955 & 0.5 & 0.28 & 1.9 \\
\hline Partner with different origin & 848 & 0.5 & 0.27 & 1.7 \\
\hline Total & 3532 & 0.5 & 0.26 & 1.8 \\
\hline \multicolumn{5}{|l|}{ Citizenship } \\
\hline German & 1596 & 0.3 & 0.17 & 1.8 \\
\hline German and foreign & 207 & 0.2 & 0.13 & 1.6 \\
\hline Foreign & 1729 & 0.7 & 0.36 & 1.9 \\
\hline Total & 3532 & 0.5 & 0.26 & 1.8 \\
\hline
\end{tabular}

Source: Mikrozensus 2008. The sample comprises women who were born in Germany as a foreigner or for whom at least one parent has an immigrant background. The latter case can only be identified if the woman still lives with at least one parent or if she provided information on her parents' origin in a $10 \%$ subsample of the Mikrozensus. 


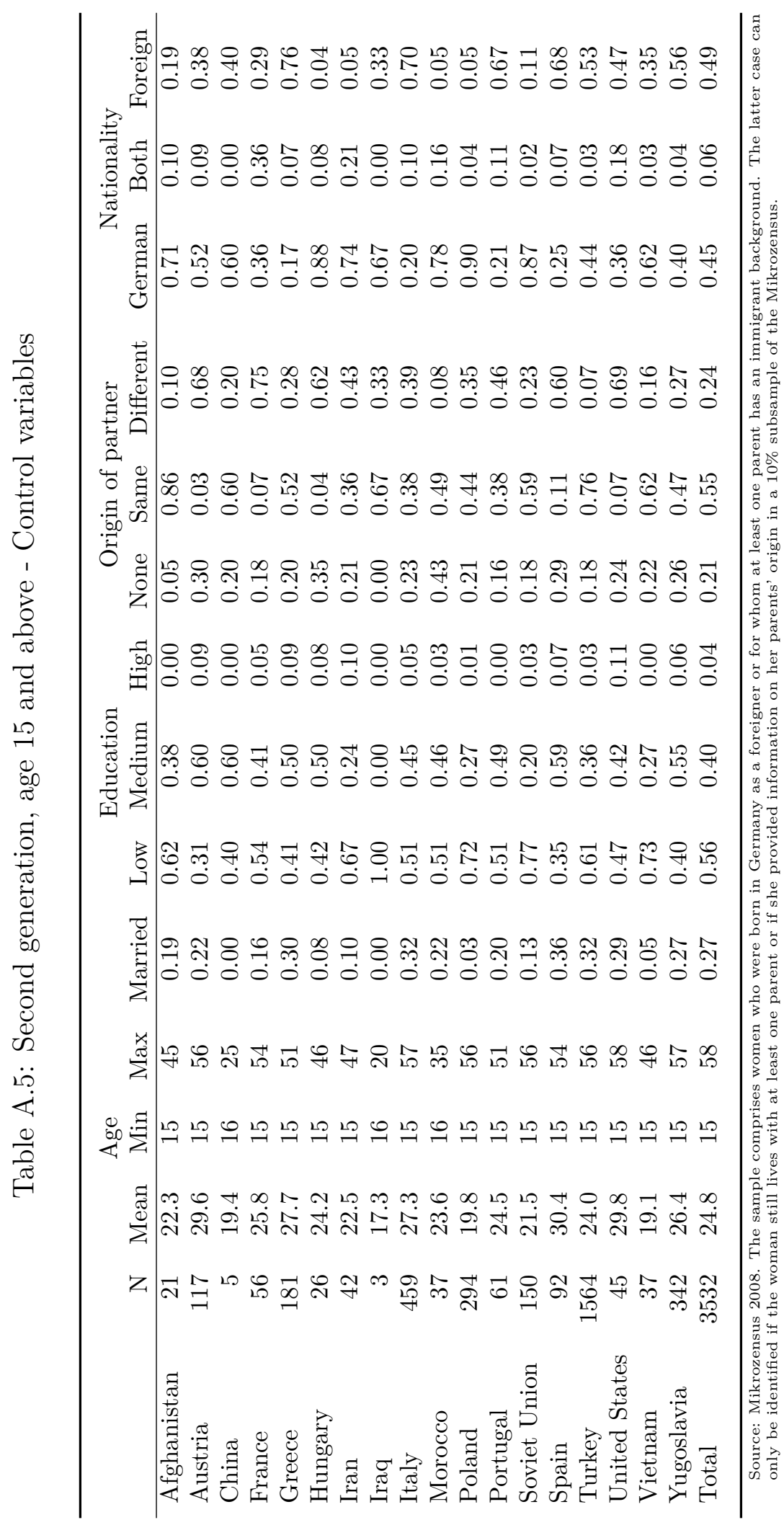


Table A.6: Second generation, age 45 and above - Number of children

\begin{tabular}{|c|c|c|c|c|}
\hline & $\mathrm{N}$ & $\begin{array}{l}\text { Avg. nb. of } \\
\text { children }\end{array}$ & $\begin{array}{l}\text { Share of women } \\
\text { with children }\end{array}$ & $\begin{array}{l}\text { Avg. nb. of children } \\
\text { (women with children only) }\end{array}$ \\
\hline \multicolumn{5}{|l|}{ Country of origin } \\
\hline Afghanistan & 1 & 3.0 & 1.00 & 3.0 \\
\hline Austria & 16 & 1.3 & 0.63 & 2.1 \\
\hline France & 5 & 1.2 & 0.80 & 1.5 \\
\hline Greece & 5 & 1.6 & 0.80 & 2.0 \\
\hline Hungary & 2 & 0.0 & 0.00 & \\
\hline Iran & 2 & 0.5 & 0.50 & 1.0 \\
\hline Italy & 15 & 1.7 & 0.73 & 2.4 \\
\hline Poland & 4 & 0.5 & 0.50 & 1.0 \\
\hline Portugal & 1 & 1.0 & 1.00 & 1.0 \\
\hline Soviet Union & 9 & 1.2 & 0.78 & 1.6 \\
\hline Spain & 7 & 2.0 & 0.86 & 2.3 \\
\hline Turkey & 8 & 2.3 & 0.88 & 2.6 \\
\hline United States & 7 & 1.1 & 0.57 & 2.0 \\
\hline Vietnam & 1 & 1.0 & 1.00 & 1.0 \\
\hline Yugoslavia & 10 & 1.8 & 0.70 & 2.6 \\
\hline Total & 93 & 1.5 & 0.71 & 2.1 \\
\hline \multicolumn{5}{|l|}{ Education } \\
\hline Low & 26 & 2.4 & 0.96 & 2.5 \\
\hline Medium & 58 & 1.2 & 0.66 & 1.9 \\
\hline High & 9 & 0.4 & 0.33 & 1.3 \\
\hline Total & 93 & 1.5 & 0.71 & 2.1 \\
\hline \multicolumn{5}{|l|}{ Origin of partner } \\
\hline No partner & 31 & 0.7 & 0.39 & 1.9 \\
\hline Partner with same origin & 29 & 2.3 & 1.00 & 2.3 \\
\hline Partner with different origin & 33 & 1.5 & 0.76 & 1.9 \\
\hline Total & 93 & 1.5 & 0.71 & 2.1 \\
\hline \multicolumn{5}{|l|}{ Citizenship } \\
\hline German & 29 & 1.1 & 0.62 & 1.7 \\
\hline German and foreign & 3 & 1.0 & 0.67 & 1.5 \\
\hline Foreign & 61 & 1.7 & 0.75 & 2.3 \\
\hline Total & 93 & 1.5 & 0.71 & 2.1 \\
\hline
\end{tabular}

Source: Mikrozensus 2008. The sample comprises women who were born in Germany as a foreigner or for whom at least one parent has an immigrant background. The latter case can only be identified if the woman still lives with at least one parent or if she provided information on her parents' origin in a $10 \%$ subsample of the Mikrozensus. 


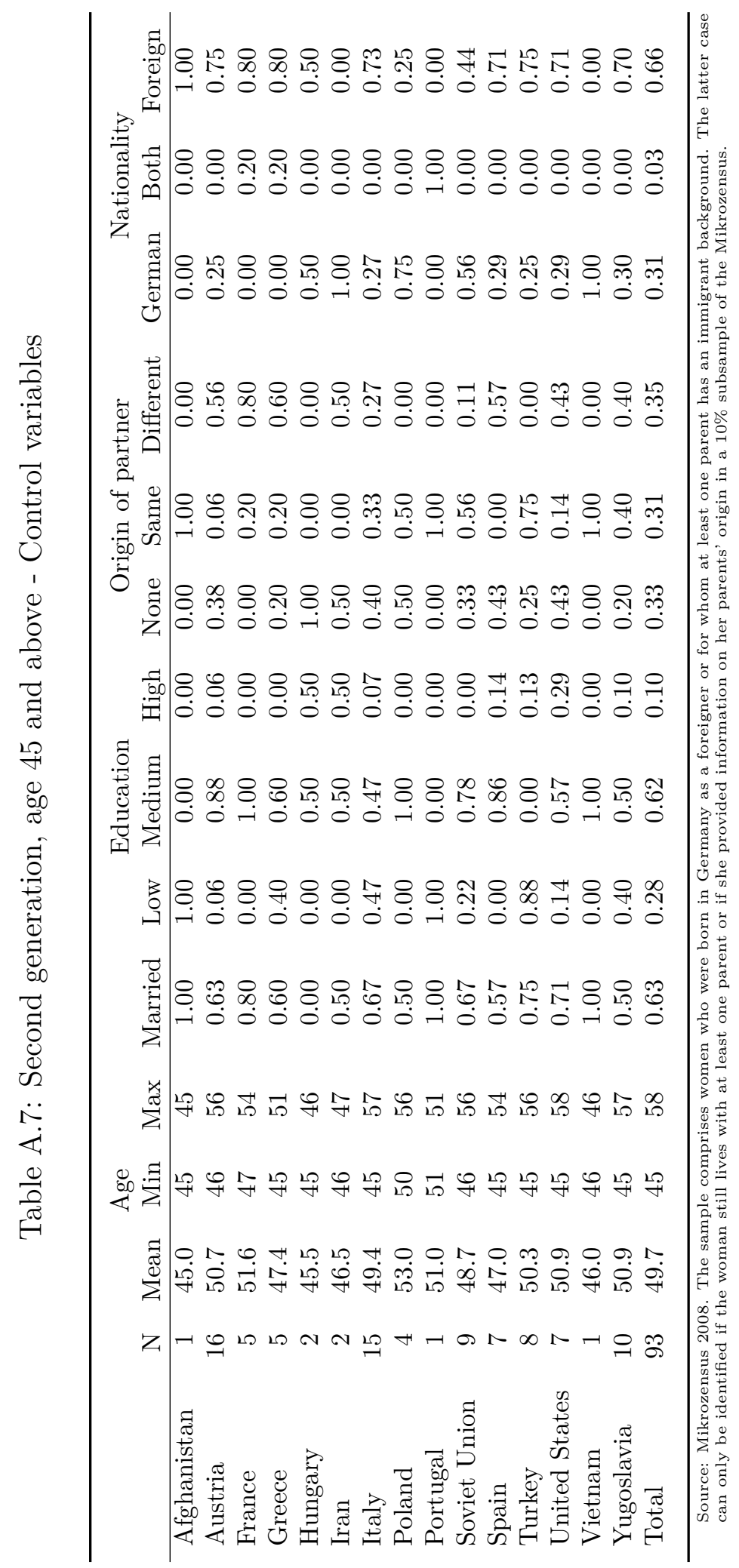




\section{A.1.3 Country-level variables}

Figure A.1: Total fertility rates (TFR)

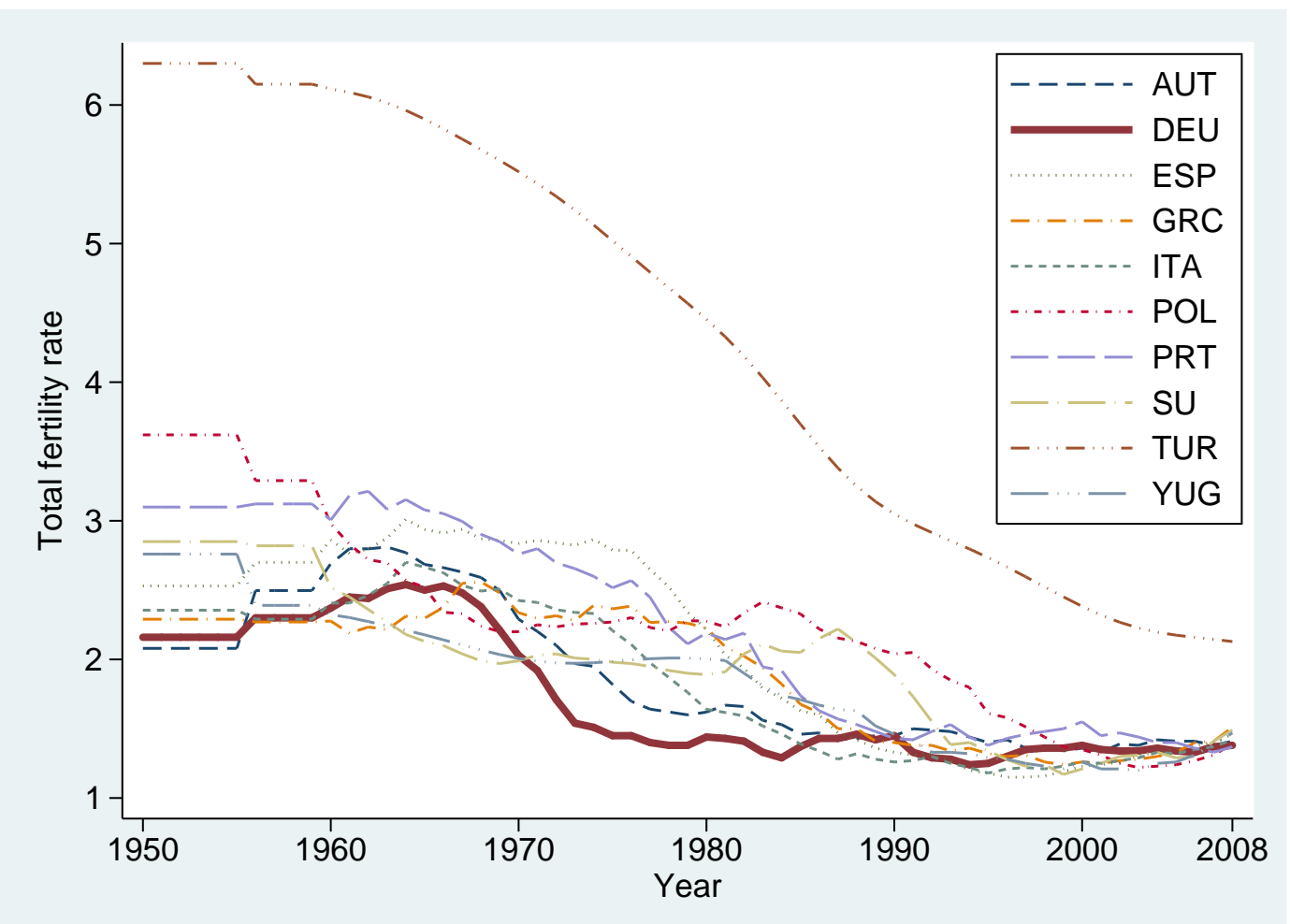

Source: World Bank (2012); UN Population Division (2011)

Table A.8: Completed cohort fertility rates

\begin{tabular}{lccccccc}
\hline & \multicolumn{7}{c}{ Year of birth } \\
Country & 1950 & 1960 & 1970 & 1975 & 1978 & 1979 & Total \\
\hline Austria & 1.89 & 1.70 & 1.61 & 1.64 & 1.59 & 1.59 & 1.67 \\
France & 2.11 & 2.13 & 2.00 & 2.02 & 2.07 & 2.08 & 2.07 \\
Germany East & 1.77 & 1.81 & 1.51 & 1.53 & 1.54 & 1.57 & 1.62 \\
Germany West & 1.71 & 1.61 & 1.52 & 1.57 & 1.55 & 1.57 & 1.59 \\
Greece & 2.00 & 1.97 & 1.64 & 1.61 & 1.62 & 1.64 & 1.75 \\
Hungary & 1.97 & 2.03 & 1.88 & 1.68 & 1.60 & 1.58 & 1.79 \\
Italy & 1.86 & 1.69 & 1.48 & 1.45 & 1.46 & 1.47 & 1.57 \\
Poland & 2.06 & 2.05 & 1.85 & 1.63 & 1.58 & 1.57 & 1.79 \\
Portugal & 2.11 & 1.94 & 1.69 & 1.57 & 1.50 & 1.47 & 1.71 \\
Soviet Union & 1.84 & 1.86 & 1.61 & 1.61 & 1.65 & 1.67 & 1.71 \\
Spain & 2.20 & 1.80 & 1.50 & 1.40 & 1.40 & 1.40 & 1.62 \\
Turkey & 4.54 & 3.51 & & & & & 4.03 \\
United States & 2.04 & 2.01 & 2.11 & 2.23 & 2.26 & 2.24 & 2.15 \\
Yugoslavia & 1.89 & 1.80 & 1.69 & 1.70 & 1.68 & 1.72 & 1.75 \\
Total & 2.14 & 1.99 & 1.70 & 1.66 & 1.65 & 1.66 & 1.81 \\
\hline$\quad$ Source: Own & & & & & & & \\
\hline
\end{tabular}

Source: Own calculations based on Hacettepe University Institute of Popul
(1999; 2009) for Turkey; Myrskylä et al. (2012) for the remaining countries. 
Figure A.2: Fertility norms - country averages
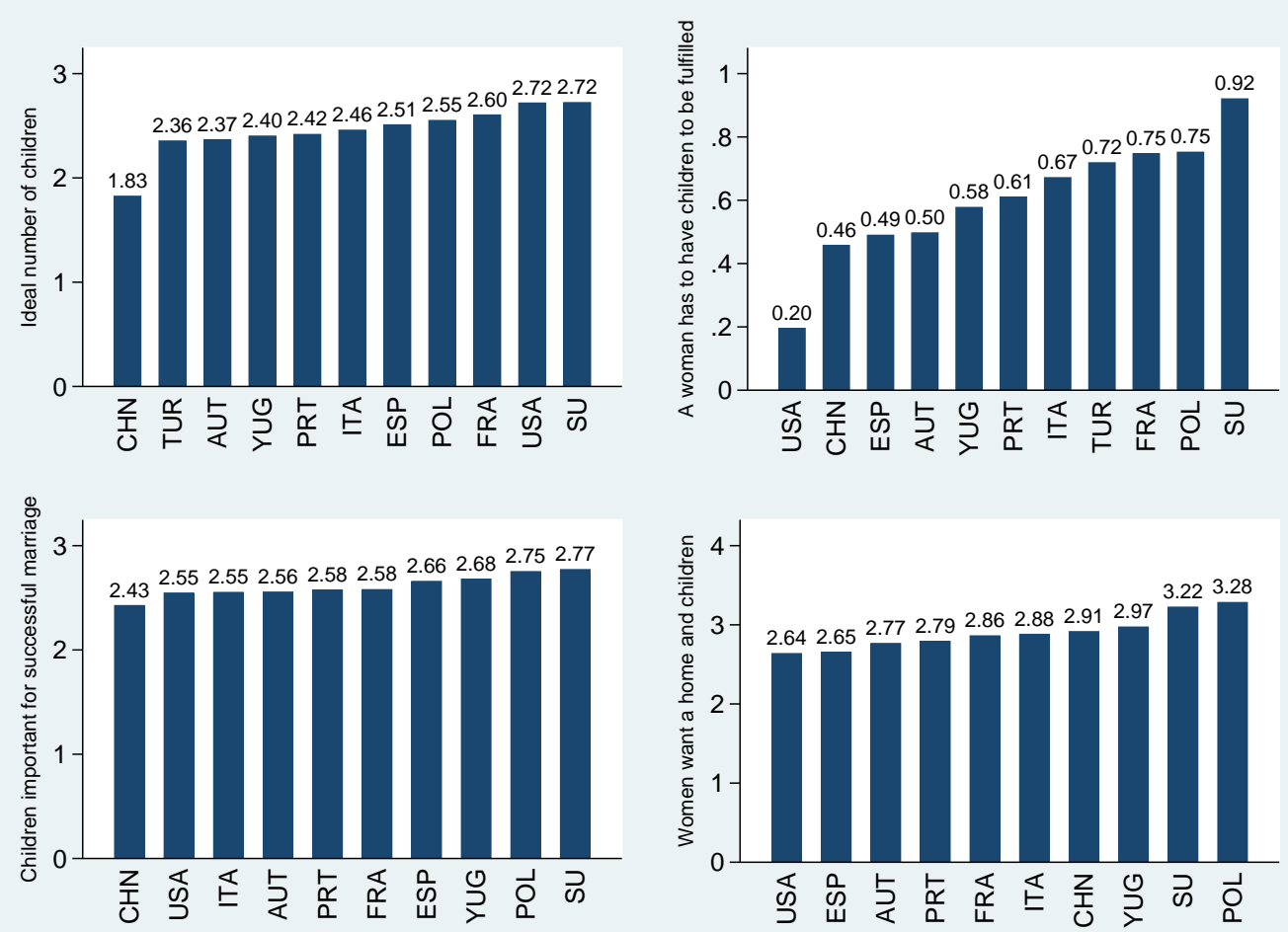

Source: World Values Survey 1990. Ideal number of children between "none" and "10 or more". Importance of children for a successful marriage: "very important", "rather important", "not very important". Children necessary for a woman's fulfillment: "needs children" and "not necessary"; "don't know" coded as missing. "Women really want a home and children": "strongly agree", "agree", "disagree" and "strongly disagree". We recoded all variables so that higher values stand for a greater importance attached to children. 
Table A.9: Fertility norms - piecewise correlations

\begin{tabular}{lcccc}
\hline \multicolumn{1}{c}{ Variables } & $(1)$ & $(2)$ & $(3)$ & (4) \\
\hline (1) Ideal number of children & 1.00 & & & \\
(2) A woman has to have children to be fulfilled & 0.21 & 1.00 & & \\
(3) Children important for successful marriage & 0.65 & 0.61 & 1.00 & \\
(4) Women want a home and children & 0.08 & 0.77 & 0.62 & 1.00 \\
\hline
\end{tabular}

Source: World Values Survey 1990

Figure A.3: TFR and fertility norms in 1990
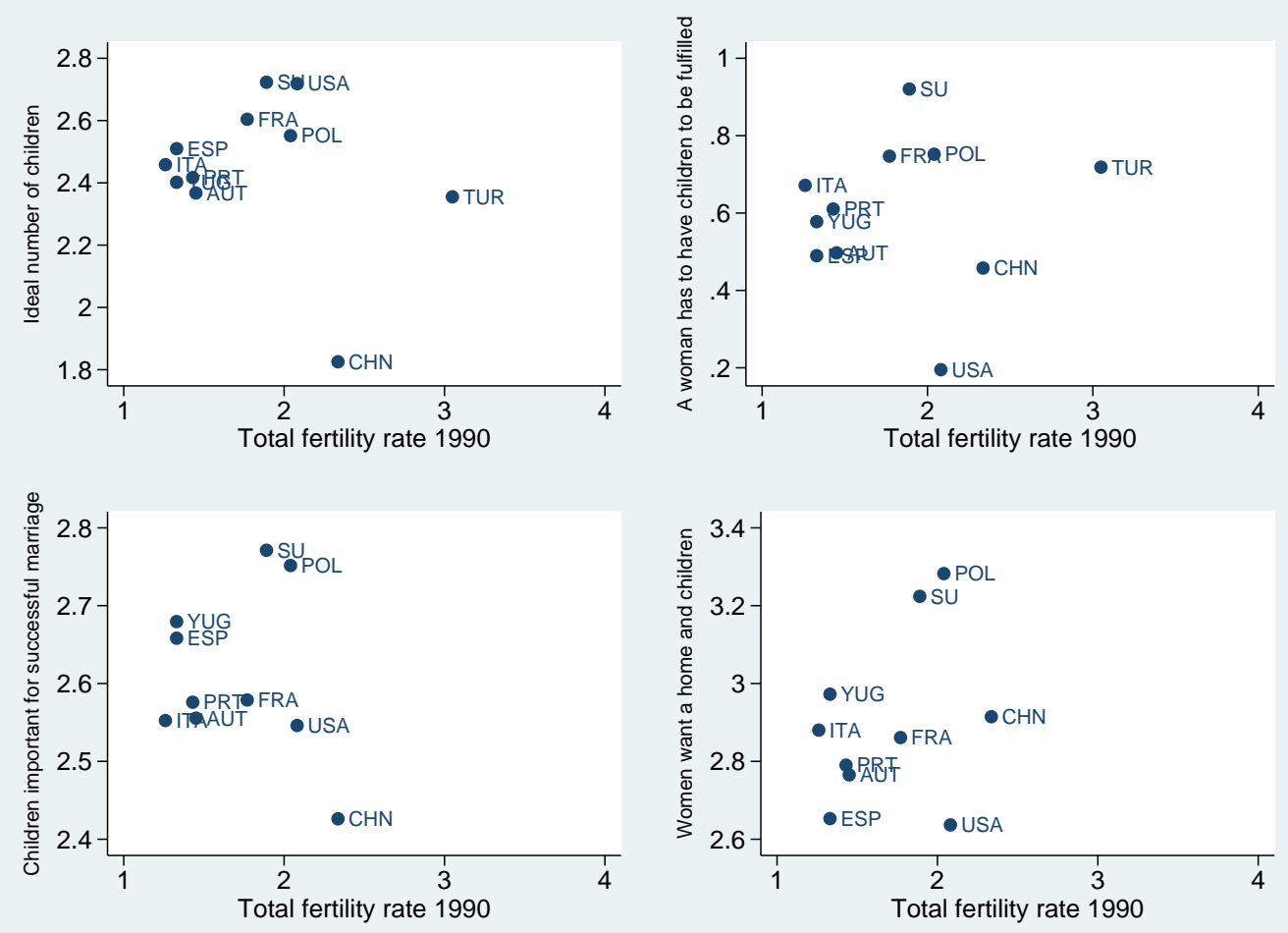

Source: World Bank (2012); UN Population Division (2011); World Values Survey 1990. Ideal number of children between "none" and "10 or more". Importance of children for a successful marriage: "very important", "rather important", "not very important". Children necessary for a woman's fulfillment: "needs children" and "not necessary"; "don't know" coded as missing. "Women really want a home and children": "strongly agree", "agree", "disagree" and "strongly disagree". We recoded all variables so that higher values stand for a greater importance attached to children. 


\section{A.2 Interaction of TFR and education level}

Table A.10: First generation - Interaction with education level

\begin{tabular}{|c|c|c|c|c|c|c|c|c|}
\hline \multirow[b]{2}{*}{ Total fertility rate (TFR) } & \multicolumn{2}{|c|}{ (1) } & \multicolumn{2}{|c|}{$(2)$} & \multicolumn{2}{|c|}{$(3)$} & \multicolumn{2}{|l|}{ (4) } \\
\hline & $0.38^{* * *}$ & $(0.05)$ & $0.36^{* * *}$ & $(0.06)$ & $0.99^{* * *}$ & $(0.29)$ & $0.98^{* * *}$ & $(0.29)$ \\
\hline TFR * Medium education & $-0.16^{* * *}$ & $(0.04)$ & -0.11 & $(0.11)$ & $-0.12^{* * *}$ & $(0.04)$ & $-0.18^{*}$ & $(0.10)$ \\
\hline TFR $*$ High education & $-0.18^{* * *}$ & $(0.05)$ & -0.09 & $(0.13)$ & -0.07 & $(0.05)$ & 0.04 & $(0.13)$ \\
\hline Age & -0.02 & $(0.01)$ & -0.02 & $(0.01)$ & $-0.05^{* * *}$ & $(0.02)$ & $-0.05^{* * *}$ & $(0.02)$ \\
\hline Age at migration & -0.07 & $(0.06)$ & -0.07 & $(0.06)$ & -0.03 & $(0.06)$ & -0.03 & $(0.06)$ \\
\hline Medium education & & & -0.17 & $(0.32)$ & & & 0.21 & $(0.30)$ \\
\hline High education & & & -0.44 & $(0.59)$ & & & -0.50 & $(0.55)$ \\
\hline Intercept & $2.84^{* *}$ & $(1.23)$ & $2.93^{* *}$ & $(1.27)$ & -3.06 & $(2.32)$ & -3.21 & $(2.32)$ \\
\hline Bundesland Fixed Effec & Yes & & Yes & & Yes & & Yes & \\
\hline Country of Origin Fixed Effects & No & & No & & Yes & & Yes & \\
\hline $\mathrm{R}^{2}$ & 0.21 & & 0.21 & & 0.27 & & 0.27 & \\
\hline Observations & 529 & & 529 & & 529 & & 529 & \\
\hline
\end{tabular}

Note: Mikrozensus 2008. The dependent variable is the number of children. The models are estimated using Ordinary Least Squares. The sample includes women age 45 and above who immigrated between the ages of 15 and 18. Standard errors clustered at the country-migration year level. Medium education: upper secondary degree or some professional training; High education: tertiary education; omitted reference category: no degree or the equivalent of the German Hauptschule and Realschule. ${ }^{*} \mathrm{p}<0.1,{ }^{* *} \mathrm{p}<0.05, * * * \mathrm{p}<0.01$

Table A.11: Second generation, age 45 and above - Interaction with education level

\begin{tabular}{|c|c|c|c|c|c|c|c|c|}
\hline \multirow[b]{2}{*}{ Total fertility rate (TFR) } & \multicolumn{2}{|c|}{ (1) } & \multicolumn{2}{|c|}{$(2)$} & \multicolumn{2}{|c|}{ (3) } & \multicolumn{2}{|c|}{$(4)$} \\
\hline & $0.19^{* *}$ & $(0.08)$ & 0.03 & $(0.13)$ & 1.15 & $(1.01)$ & 0.73 & $(1.02)$ \\
\hline TFR * Medium education & $-0.30^{* * *}$ & $(0.10)$ & -0.08 & $(0.17)$ & $-0.36^{* *}$ & $(0.18)$ & 0.01 & $(0.39)$ \\
\hline TFR * High education & $-0.36^{* * *}$ & $(0.09)$ & 0.16 & $(0.14)$ & $-0.38^{* * *}$ & $(0.13)$ & 0.22 & $(0.23)$ \\
\hline Age & 0.03 & $(0.03)$ & 0.03 & $(0.03)$ & $0.06^{*}$ & $(0.04)$ & 0.06 & $(0.04)$ \\
\hline Medium education & & & -0.89 & $(0.81)$ & & & -1.16 & $(1.21)$ \\
\hline High education & & & $-2.22^{* * *}$ & $(0.70)$ & & & $-2.37^{* *}$ & $(0.95)$ \\
\hline Intercept & -1.39 & $(1.80)$ & -0.77 & $(1.95)$ & $-5.09^{* *}$ & $(2.44)$ & -3.96 & $(2.41)$ \\
\hline Bundesland Fixed Effects & Yes & & Yes & & Yes & & Yes & \\
\hline Country of Origin Fixed Effects & No & & No & & Yes & & Yes & \\
\hline $\mathrm{R}^{2}$ & 0.28 & & 0.31 & & 0.38 & & 0.40 & \\
\hline Observations & 93 & & 93 & & 93 & & 93 & \\
\hline
\end{tabular}

Note: Mikrozensus 2008. The dependent variable is the number of children. The models are estimated using Ordinary Least Squares. Standard errors clustered at the country-year of birth level. Medium education: upper secondary degree or some professional training; High education: tertiary education; omitted reference category: no degree or the equivalent of the German Hauptschule and Realschule. * $\mathrm{p}<0.1,{ }^{* *} \mathrm{p}<0.05$, $* * * \mathrm{p}<0.01$ 
Table A.12: Second generation, age 15 and above - Interaction with education level

\begin{tabular}{|c|c|c|c|c|c|c|c|c|}
\hline \multirow[b]{2}{*}{ Total fertility rate (TFR) } & \multicolumn{2}{|c|}{ (1) } & \multicolumn{2}{|c|}{ (2) } & \multicolumn{2}{|c|}{ (3) } & \multicolumn{2}{|c|}{ (4) } \\
\hline & $0.13^{* * *}$ & $(0.02)$ & $0.07^{* * *}$ & $(0.02)$ & $0.43^{* * *}$ & $(0.06)$ & $0.37^{* * *}$ & $(0.07)$ \\
\hline TFR * Medium education & $-0.11^{* * *}$ & $(0.01)$ & -0.03 & $(0.02)$ & $-0.11^{* * *}$ & $(0.01)$ & $-0.08^{* * *}$ & $(0.02)$ \\
\hline TFR * High education & $-0.27^{* * *}$ & $(0.02)$ & $-0.08^{*}$ & $(0.04)$ & $-0.28 * * *$ & $(0.02)$ & $-0.14^{* * *}$ & $(0.05)$ \\
\hline Age & $0.13^{* * *}$ & $(0.02)$ & $0.15^{* * *}$ & $(0.02)$ & $0.08^{* * *}$ & $(0.02)$ & $0.10^{* * *}$ & $(0.02)$ \\
\hline $\mathrm{Age}^{2}$ & $-0.00^{* * *}$ & $(0.00)$ & $-0.00^{* * *}$ & $(0.00)$ & $-0.00^{*}$ & $(0.00)$ & $-0.00^{* *}$ & $(0.00)$ \\
\hline Medium education & & & $-0.31 * * *$ & $(0.08)$ & & & $-0.13^{*}$ & $(0.08)$ \\
\hline High education & & & $-0.77 * * *$ & $(0.15)$ & & & $-0.53^{* * *}$ & $(0.17)$ \\
\hline Intercept & $-2.28^{* * *}$ & $(0.22)$ & $-2.39^{* * *}$ & $(0.23)$ & $-1.72^{* * *}$ & $(0.23)$ & $-1.84^{* * *}$ & $(0.24)$ \\
\hline Bundesland Fixed Effects & Yes & & Yes & & Yes & & Yes & \\
\hline Country of Origin Fixed Effects & No & & No & & Yes & & Yes & \\
\hline $\mathrm{R}^{2}$ & 0.43 & & 0.44 & & 0.45 & & 0.45 & \\
\hline Observations & 3532 & & 3532 & & 3532 & & 3532 & \\
\hline
\end{tabular}

Note: Mikrozensus 2008. The dependent variable is the number of children. The models are estimated using Ordinary Least Squares. Standard errors clustered at the country-year of birth level. Medium education: upper secondary degree or some professional training; High education: tertiary education; omitted reference category: no degree or the equivalent of the German Hauptschule and Realschule. ${ }^{*} \mathrm{p}<0.1, * * \mathrm{p}<0.05$, $* * * \mathrm{p}<0.01$

Table A.13: Generations 1.5 and 2, age 45 and above - Interaction with education level

\begin{tabular}{|c|c|c|c|c|c|c|c|c|}
\hline \multirow[b]{2}{*}{ Total fertility rate (TFR) } & \multicolumn{2}{|c|}{ (1) } & \multicolumn{2}{|c|}{$(2)$} & \multicolumn{2}{|c|}{ (3) } & \multicolumn{2}{|l|}{ (4) } \\
\hline & $0.23^{* * *}$ & $(0.03)$ & $0.16^{* * *}$ & $(0.05)$ & 0.27 & $(0.31)$ & 0.13 & $(0.32)$ \\
\hline TFR * Medium education & $-0.15^{* * *}$ & $(0.04)$ & 0.03 & $(0.09)$ & $-0.11^{* * *}$ & $(0.04)$ & 0.07 & $(0.07)$ \\
\hline TFR $*$ High education & $-0.30^{* * *}$ & $(0.05)$ & -0.18 & $(0.11)$ & $-0.26^{* * *}$ & $(0.06)$ & -0.13 & $(0.15)$ \\
\hline Age & 0.00 & $(0.01)$ & 0.00 & $(0.01)$ & 0.01 & $(0.02)$ & 0.00 & $(0.02)$ \\
\hline Medium education & & & $-0.73^{* *}$ & $(0.30)$ & & & $-0.76^{* * *}$ & $(0.28)$ \\
\hline High education & & & -0.55 & $(0.42)$ & & & -0.57 & $(0.53)$ \\
\hline Intercept & 0.88 & $(0.96)$ & 1.29 & $(0.98)$ & 0.30 & $(0.76)$ & 0.84 & $(0.79)$ \\
\hline Bundesland Fixed Effects & Yes & & Yes & & Yes & & Yes & \\
\hline Country of Origin Fixed Effects & No & & No & & Yes & & Yes & \\
\hline $\mathrm{R}^{2}$ & 0.19 & & 0.20 & & 0.24 & & 0.25 & \\
\hline Observations & 495 & & 495 & & 495 & & 495 & \\
\hline
\end{tabular}

Note: Mikrozensus 2008. The dependent variable is the number of children. The models are estimated using Ordinary Least Squares. Standard errors clustered at the country-year of birth level. Medium education: upper secondary degree or some professional training; High education: tertiary education; omitted reference category: no degree or the equivalent of the German Hauptschule and Realschule. ${ }^{*} \mathrm{p}<0.1$, $* * \mathrm{p}<0.05$, $* * * \mathrm{p}<0.01$ 


\section{A.3 Origin of the partner}

Table A.14: First generation - By origin of the partner

\begin{tabular}{|c|c|c|c|c|c|c|c|c|}
\hline \multirow[b]{3}{*}{ Total fertility rate (TFR) } & \multicolumn{4}{|c|}{ Lives with partner } & \multicolumn{4}{|c|}{ Partner from different origin } \\
\hline & \multicolumn{2}{|c|}{ Pooled } & \multicolumn{2}{|c|}{ Within } & \multicolumn{2}{|c|}{ Pooled } & \multicolumn{2}{|c|}{ Within } \\
\hline & $0.33^{* * *}$ & $(0.06)$ & $1.01^{* * *}$ & $(0.35)$ & 0.18 & $(0.21)$ & $0.82^{*}$ & $(0.44)$ \\
\hline TFR x Partner with different origin & $-0.26^{* * *}$ & $(0.07)$ & -0.13 & $(0.11)$ & & & & \\
\hline TFR x Partner of German origin & & & & & -0.14 & $(0.11)$ & -0.16 & $(0.18)$ \\
\hline Age & -0.00 & $(0.01)$ & $-0.04^{* *}$ & $(0.02)$ & $-0.05^{* *}$ & $(0.02)$ & $-0.07^{* * *}$ & $(0.02)$ \\
\hline Age at migration & -0.06 & $(0.06)$ & -0.00 & $(0.07)$ & -0.11 & $(0.11)$ & -0.12 & $(0.14)$ \\
\hline Medium education & $-0.41^{* * *}$ & $(0.13)$ & $-0.36^{* *}$ & $(0.14)$ & -0.34 & $(0.32)$ & -0.43 & $(0.36)$ \\
\hline High education & $-0.86^{* * *}$ & $(0.27)$ & $-0.51^{*}$ & $(0.26)$ & -0.08 & $(0.47)$ & -0.56 & $(0.66)$ \\
\hline Intercept & 2.03 & $(1.33)$ & -3.73 & $(2.80)$ & 3.96 & $(2.41)$ & 0.99 & $(4.57)$ \\
\hline Bundesland Fixed Effects & Yes & & Yes & & Yes & & Yes & \\
\hline Country of Origin Fixed Effects & No & & Yes & & No & & Yes & \\
\hline $\mathrm{R}^{2}$ & 0.26 & & 0.31 & & 0.23 & & 0.30 & \\
\hline Observations & 418 & & 418 & & 89 & & 89 & \\
\hline
\end{tabular}

Note: Mikrozensus 2008. The dependent variable is the number of children. The models are estimated using Ordinary Least Squares. The sample includes women age 45 and above who immigrated between the ages of 15 and 18 . Standard errors clustered at the country-migration year level. Medium education: upper secondary degree or some professional training; High education: tertiary education; omitted reference category: no degree or the equivalent of the German Hauptschule and Realschule. * $\mathrm{p}<0.1,{ }^{* *} \mathrm{p}<0.05,{ }^{* * *} \mathrm{p}<0.01$ 
Table A.15: Second generation, age 45 and above - By origin of the partner

\begin{tabular}{lrrrrrrrrr}
\hline & \multicolumn{3}{c}{ Lives with partner } & \multicolumn{3}{c}{ Partner from different origin } \\
& \multicolumn{2}{c}{ Pooled } & \multicolumn{2}{c}{ Within } & \multicolumn{2}{c}{ Pooled } & \multicolumn{2}{c}{ Within } \\
\hline Total fertility rate (TFR) & 0.02 & $(0.10)$ & 0.31 & $(1.57)$ & -0.01 & $(0.23)$ & -1.90 & $(4.15)$ \\
TFR x Partner with different origin & -0.05 & $(0.09)$ & $-0.36^{*}$ & $(0.21)$ & & & & \\
TFR x Partner of German origin & & & & & $0.34^{* *}$ & $(0.16)$ & -0.03 & $(0.47)$ \\
Age & -0.01 & $(0.04)$ & -0.01 & $(0.06)$ & -0.03 & $(0.08)$ & -0.18 & $(0.24)$ \\
Medium education & $-1.21^{* * *}$ & $(0.44)$ & $-1.16^{*}$ & $(0.68)$ & $-1.29^{* * *}$ & $(0.41)$ & $-2.46^{* *}$ & $(1.01)$ \\
High education & $-1.56^{* *}$ & $(0.59)$ & $-2.00^{* * *}$ & $(0.74)$ & $-2.35^{* * *}$ & $(0.58)$ & $-4.19^{* * *}$ & $(1.41)$ \\
Intercept & 1.61 & $(2.75)$ & 2.27 & $(5.72)$ & 1.84 & $(4.27)$ & 18.32 & $(23.11)$ \\
Bundesland Fixed Effects & Yes & & Yes & & Yes & & Yes & \\
Country of Origin Fixed Effects & No & & Yes & & No & & Yes & \\
$\mathrm{R}^{2}$ & 0.31 & 62 & 0.43 & & 0.31 & & 0.52 & \\
Observations & 62 & 62 & & 33 & & 33 \\
\hline
\end{tabular}

Note: Mikrozensus 2008. The dependent variable is the number of children. The models are estimated using Ordinary Least Squares. Standard errors (in parentheses) clustered at the country-year of birth level. Medium education: upper secondary degree or some professional training; High education: tertiary education; omitted reference category: no degree or the equivalent of the German Hauptschule and Realschule. ${ }^{*} \mathrm{p}<0.1,{ }^{* *} \mathrm{p}<0.05,{ }^{* * *} \mathrm{p}<0.01$

Table A.16: Second generation, age 15 and above - By origin of the partner

\begin{tabular}{|c|c|c|c|c|c|c|c|c|}
\hline \multirow{5}{*}{$\begin{array}{l}\text { Total fertility rate }(\mathrm{TFR}) \\
\text { TFR x Partner with different origin } \\
\text { TFR x Partner of German origin }\end{array}$} & \multicolumn{4}{|c|}{ Lives with partner } & \multicolumn{4}{|c|}{ Partner from different origin } \\
\hline & \multicolumn{2}{|c|}{ Pooled } & \multicolumn{2}{|c|}{ Within } & \multicolumn{2}{|c|}{ Pooled } & \multicolumn{2}{|c|}{ Within } \\
\hline & $0.06^{* * *}$ & $(0.02)$ & $0.30 * * *$ & $(0.06)$ & 0.02 & $(0.02)$ & $0.23^{* *}$ & $(0.09)$ \\
\hline & $-0.04^{* * *}$ & $(0.01)$ & $-0.05^{* * *}$ & $(0.01)$ & & & & \\
\hline & & & & & 0.03 & $(0.02)$ & 0.03 & $(0.02)$ \\
\hline Age & $0.16^{* * *}$ & $(0.02)$ & $0.11^{* * *}$ & $(0.02)$ & $0.15^{* * *}$ & $(0.03)$ & $0.12^{* * *}$ & $(0.03)$ \\
\hline Age $^{2}$ & $-0.00^{* * *}$ & $(0.00)$ & $-0.00 * *$ & $(0.00)$ & $-0.00 * * *$ & $(0.00)$ & $-0.00 * *$ & $(0.00)$ \\
\hline Medium education & $-0.39 * * *$ & $(0.05)$ & $-0.37^{* * *}$ & $(0.05)$ & $-0.41^{* * *}$ & $(0.08)$ & $-0.38^{* * *}$ & $(0.08)$ \\
\hline High education & $-0.96^{* * *}$ & $(0.10)$ & $-0.95^{* * *}$ & $(0.11)$ & $-0.87 * * *$ & $(0.15)$ & $-0.84^{* * *}$ & $(0.15)$ \\
\hline Intercept & $-2.51^{* * *}$ & $(0.26)$ & $-2.06^{* * *}$ & $(0.28)$ & $-2.36^{* * *}$ & $(0.36)$ & $-2.18^{* * *}$ & $(0.39)$ \\
\hline Bundesland Fixed Effects & Yes & & Yes & & Yes & & Yes & \\
\hline Country of Origin Fixed Effects & No & & Yes & & No & & Yes & \\
\hline $\mathrm{R}^{2}$ & 0.51 & & 0.52 & & 0.47 & & 0.49 & \\
\hline Observations & 2803 & & 2803 & & 846 & & 846 & \\
\hline
\end{tabular}
Note: Mikrozensus 2008. The dependent variable is the number of children. The models are estimated using Ordinary Least Squares. Standard errors
(in parentheses) clustered at the country-year of birth level. Medium education: upper secondary degree or some professional training; High education:
tertiary education; omitted reference category: no degree or the equivalent of the German Hauptschule and Realschule. ${ }^{*}$ p $<0.1,{ }^{* *}$ p $<0.05, * * * 0.01$ 
Table A.17: Generations 1.5 and 2, age 45 and above - By origin of the partner

\begin{tabular}{|c|c|c|c|c|c|c|c|c|}
\hline \multirow{5}{*}{$\begin{array}{l}\text { Total fertility rate }(\mathrm{TFR}) \\
\text { TFR x Partner with different origin } \\
\text { TFR x Partner of German origin }\end{array}$} & \multicolumn{4}{|c|}{ Lives with partner } & \multicolumn{4}{|c|}{ Partner from different origin } \\
\hline & \multicolumn{2}{|c|}{ Pooled } & \multicolumn{2}{|c|}{ Within } & \multicolumn{2}{|c|}{ Pooled } & \multicolumn{2}{|c|}{ Within } \\
\hline & $0.16^{* * *}$ & $(0.04)$ & 0.34 & $(0.34)$ & 0.09 & $(0.09)$ & 0.42 & $(0.38)$ \\
\hline & $-0.12^{* * *}$ & $(0.04)$ & $-0.09 *$ & $(0.05)$ & & & & \\
\hline & & & & & -0.01 & $(0.07)$ & 0.02 & $(0.08)$ \\
\hline Age & 0.00 & $(0.02)$ & -0.01 & $(0.02)$ & -0.03 & $(0.02)$ & -0.04 & $(0.03)$ \\
\hline Medium education & $-0.37 * * *$ & $(0.14)$ & $-0.30 * *$ & $(0.14)$ & -0.29 & $(0.25)$ & -0.35 & $(0.26)$ \\
\hline High education & $-0.64^{* * *}$ & $(0.20)$ & $-0.54^{* *}$ & $(0.22)$ & $-0.55^{*}$ & $(0.29)$ & $-0.65^{* *}$ & $(0.31)$ \\
\hline Intercept & 1.44 & $(1.12)$ & 0.74 & $(0.82)$ & $2.00^{*}$ & $(1.19)$ & 1.76 & $(1.25)$ \\
\hline Bundesland Fixed Effects & Yes & & Yes & & Yes & & Yes & \\
\hline Country of Origin Fixed Effects & No & & Yes & & No & & Yes & \\
\hline $\mathrm{R}^{2}$ & 0.20 & & 0.26 & & 0.11 & & 0.17 & \\
\hline Observations & 354 & & 354 & & 174 & & 174 & \\
\hline
\end{tabular}

Note: Mikrozensus 2008. The dependent variable is the number of children. The models are estimated using Ordinary Least Squares. Standard errors (in parentheses) clustered at the country-year of birth level. Medium education: upper secondary degree or some professional training;
High education: tertiary education; omitted reference category: no degree or the equivalent of the German Hauptschule and Realschule. *p $<0.1$, $* * \mathrm{p}<0.05, * * * \mathrm{p}<0.01$ 


\section{A.4 Interaction terms for mixed origin}

Table A.18: Second generation, age 15 and above - With interaction terms for mixed origin

\begin{tabular}{|c|c|c|c|c|c|c|}
\hline \multirow[b]{2}{*}{ Total fertility rate } & \multicolumn{2}{|c|}{ No controls } & \multicolumn{2}{|c|}{ Pooled } & \multicolumn{2}{|c|}{ Within } \\
\hline & $0.04^{* * *}$ & $(0.02)$ & 0.00 & $(0.01)$ & $0.13^{* *}$ & $(0.06)$ \\
\hline TFR x Only mother from the country & 0.00 & $(0.01)$ & 0.01 & $(0.01)$ & 0.01 & $(0.01)$ \\
\hline TFR $x$ Both parents from the country & $0.02^{* * *}$ & $(0.01)$ & $0.02^{* * *}$ & $(0.01)$ & $0.03^{* * *}$ & $(0.01)$ \\
\hline Age & & & $-0.06 * *$ & $(0.03)$ & $-0.07 * * *$ & $(0.03)$ \\
\hline $\mathrm{Age}^{2}$ & & & $0.00^{* * *}$ & $(0.00)$ & $0.00 * * *$ & $(0.00)$ \\
\hline Medium education & & & $-0.10 * *$ & $(0.04)$ & $-0.09 * *$ & $(0.04)$ \\
\hline High education & & & $-0.44^{* * *}$ & $(0.09)$ & $-0.42^{* * *}$ & $(0.09)$ \\
\hline Intercept & $-0.09^{* * *}$ & $(0.04)$ & 0.48 & $(0.33)$ & -0.36 & $(0.60)$ \\
\hline Bundesland Fixed Effects & No & & Yes & & Yes & \\
\hline Country of Origin Fixed Effects & No & & No & & Yes & \\
\hline $\mathrm{R}^{2}$ & 0.04 & & 0.28 & & 0.30 & \\
\hline Observations & 1905 & & 1905 & & 1905 & \\
\hline
\end{tabular}

Note: Mikrozensus 2008. The dependent variable is the number of children. The models are estimated using Ordinary Least Squares. Standard errors (in parentheses) clustered at the country-year of birth level. Medium education: upper secondary degree or some professional training; High education: tertiary education; omitted reference category: no degree or the equivalent of the German Hauptschule and Realschule. ${ }^{*} \mathrm{p}<0.1,{ }^{* *} \mathrm{p}<0.05,{ }^{* * *} \mathrm{p}<0.01$ 


\section{A.5 Additional control variables}






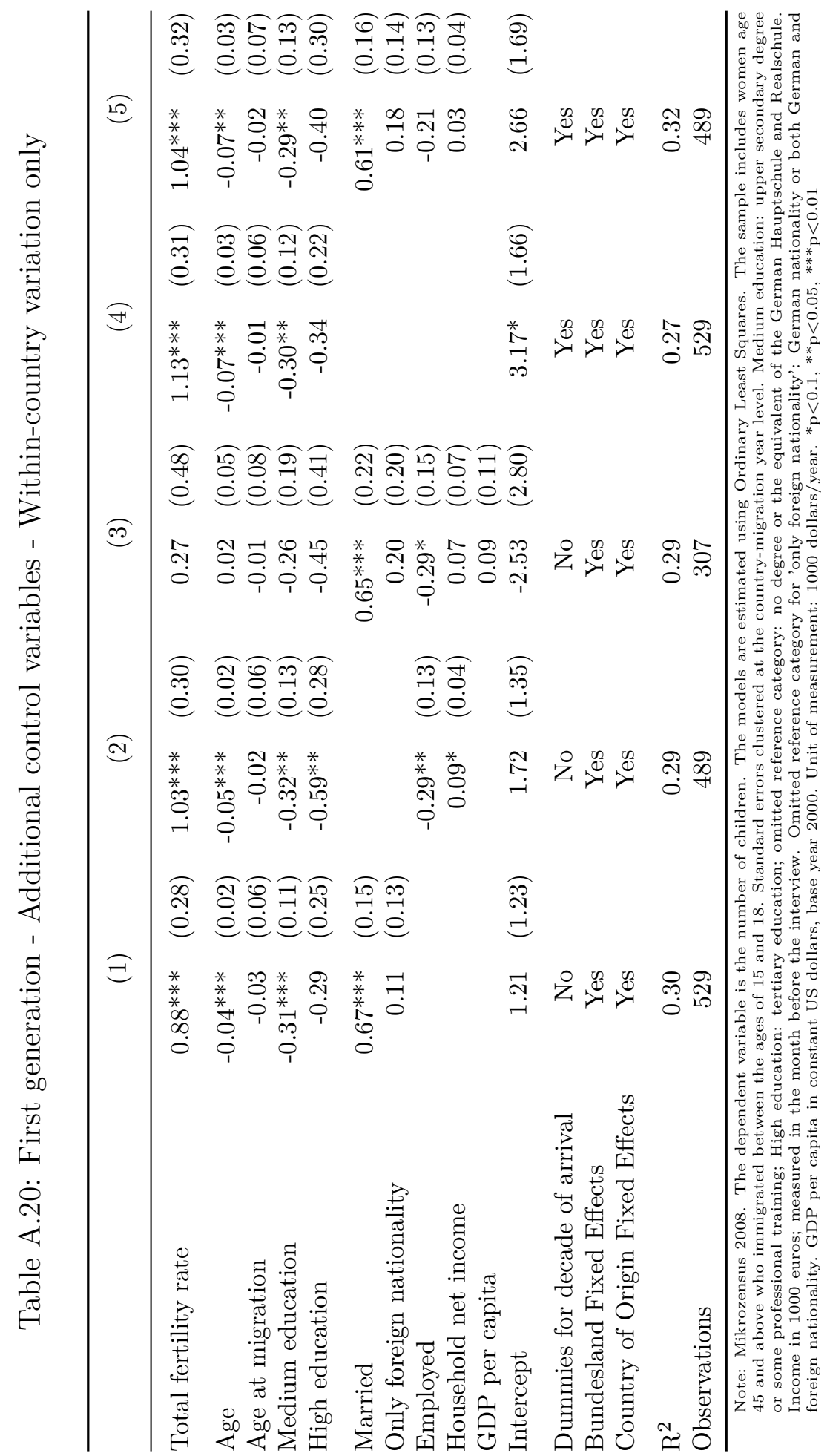


Table A.21: Second generation, age 45 and above - Additional control variables

\begin{tabular}{|c|c|c|c|c|c|c|}
\hline \multirow[b]{2}{*}{ Total fertility rate } & \multicolumn{2}{|c|}{ (1) } & \multicolumn{2}{|c|}{$(2)$} & \multicolumn{2}{|c|}{$(3)$} \\
\hline & 0.02 & $(0.08)$ & 0.02 & $(0.08)$ & 0.09 & $(0.20)$ \\
\hline Age & 0.02 & $(0.03)$ & 0.02 & $(0.03)$ & 0.14 & $(0.30)$ \\
\hline Medium education & $-1.01^{* *}$ & $(0.43)$ & $-1.16^{* *}$ & $(0.44)$ & 0.30 & $(0.69)$ \\
\hline High education & $-1.51^{* * *}$ & $(0.42)$ & $-1.75^{* * *}$ & $(0.38)$ & 0.20 & $(1.13)$ \\
\hline Married & $0.56^{*}$ & $(0.29)$ & & & -0.71 & $(0.52)$ \\
\hline Only foreign nationality & 0.38 & $(0.28)$ & & & $1.60^{*}$ & $(0.82)$ \\
\hline Employed & & & -0.15 & $(0.38)$ & -0.01 & $(0.67)$ \\
\hline Household net income & & & 0.04 & $(0.07)$ & 0.00 & $(0.22)$ \\
\hline GDP per capita & & & & & 0.07 & $(0.14)$ \\
\hline Intercept & 0.94 & $(1.88)$ & 1.42 & $(2.12)$ & -4.66 & $(13.96)$ \\
\hline Bundesland Fixed Effects & Yes & & Yes & & Yes & \\
\hline $\mathrm{R}^{2}$ & 0.36 & & 0.32 & & 0.75 & \\
\hline Observations & 93 & & 89 & & 29 & \\
\hline
\end{tabular}

Table A.22: Second generation, age 15 and above - Additional control variables

\begin{tabular}{lrrrrrr}
\hline & \multicolumn{2}{c}{$(1)$} & & $(2)$ & & $(3)$ \\
\hline Total fertility rate & 0.01 & $(0.01)$ & $0.05^{* * *}$ & $(0.01)$ & $0.03^{*}$ & $(0.01)$ \\
Age & $0.08^{* * *}$ & $(0.01)$ & $0.19^{* * *}$ & $(0.02)$ & $0.05^{* * *}$ & $(0.02)$ \\
Age $^{2}$ & $-0.00^{* *}$ & $(0.00)$ & $-0.00^{* * *}$ & $(0.00)$ & 0.00 & $(0.00)$ \\
Medium education & $-0.32^{* * *}$ & $(0.04)$ & $-0.39^{* * *}$ & $(0.04)$ & $-0.27^{* * *}$ & $(0.04)$ \\
High education & $-0.79^{* * *}$ & $(0.08)$ & $-0.98^{* * *}$ & $(0.08)$ & $-0.74^{* * *}$ & $(0.09)$ \\
Married & $0.92^{* * *}$ & $(0.05)$ & & & $0.87^{* * *}$ & $(0.06)$ \\
Only foreign nationality & 0.03 & $(0.02)$ & & & -0.00 & $(0.02)$ \\
Employed & & & $-0.33^{* * *}$ & $(0.04)$ & $-0.28^{* * *}$ & $(0.04)$ \\
Household net income & & & $0.01^{*}$ & $(0.01)$ & 0.01 & $(0.01)$ \\
GDP per capita & & & & & $0.01^{* * *}$ & $(0.00)$ \\
Intercept & $-1.24^{* * *}$ & $(0.18)$ & $-2.81^{* * *}$ & $(0.23)$ & $-1.01^{* * *}$ & $(0.24)$ \\
Bundesland Fixed Effects & Yes & & Yes & & Yes & \\
$\mathrm{R}^{2}$ & 0.56 & & 0.46 & & 0.60 & \\
Observations & 3532 & & 3234 & & 2764 & \\
\hline
\end{tabular}

Note: Mikrozensus 2008. The dependent variable is the number of children. The models are estimated using Ordinary Least Squares. Standard errors clustered at the country-year of birth level. Medium education: upper secondary degree or some professional training; High education: tertiary education; omitted reference category: no degree or the equivalent of the German Hauptschule and Realschule. Income in 1000 euros; measured in the month before the interview. Omitted reference category for 'only foreign nationality': German nationality or both German and foreign nationality. GDP per capita in constant US dollars, base year 2000. Unit of measurement: 1000 dollars/year. ${ }^{*} \mathrm{p}<0.1, * * \mathrm{p}<0.05, * * * \mathrm{p}<0.01$ 
Table A.23: Generations 1.5 and 2, age 45 and above - Additional control variables

\begin{tabular}{lrrrrrr}
\hline & \multicolumn{2}{c}{$(1)$} & & $(2)$ & & $(3)$ \\
\hline Total fertility rate & $0.15^{* * *}$ & $(0.03)$ & $0.13^{* * *}$ & $(0.03)$ & $0.18^{* * *}$ & $(0.06)$ \\
Age & -0.00 & $(0.01)$ & 0.00 & $(0.02)$ & 0.07 & $(0.06)$ \\
Medium education & $-0.57^{* * *}$ & $(0.12)$ & $-0.70^{* * *}$ & $(0.13)$ & $-0.42^{*}$ & $(0.22)$ \\
High education & $-1.06^{* * *}$ & $(0.18)$ & $-1.38^{* * *}$ & $(0.22)$ & $-1.81^{* * *}$ & $(0.27)$ \\
Married & $0.41^{* * *}$ & $(0.12)$ & & & -0.17 & $(0.23)$ \\
Only foreign nationality & 0.17 & $(0.11)$ & & & 0.13 & $(0.23)$ \\
Employed & & & -0.15 & $(0.13)$ & -0.40 & $(0.24)$ \\
Household net income & & & $0.11^{* *}$ & $(0.04)$ & 0.12 & $(0.08)$ \\
GDP per capita & & & & & -0.02 & $(0.04)$ \\
Intercept & $1.40^{*}$ & $(0.75)$ & $1.69^{* *}$ & $(0.80)$ & -1.62 & $(3.24)$ \\
Bundesland Fixed Effects & Yes & & Yes & & Yes & \\
$\mathrm{R}^{2}$ & 0.22 & & 0.21 & & 0.33 & \\
Observations & 495 & & 469 & & 155 &
\end{tabular}

Note: Mikrozensus 2008. The dependent variable is the number of children. The models are estimated using Ordinary Least Squares. Standard errors clustered at the country-year of birth level. Medium education: upper secondary degree or some professional training; High education: tertiary education; omitted reference category: no degree or the equivalent of the German Hauptschule and Realschule. Income in 1000 euros; measured in the month before the interview. Omitted reference category for 'only foreign nationality': German nationality or both German and foreign nationality. GDP per capita in constant US dollars, base year 2000. Unit of measurement: 1000 dollars /year. ${ }^{*} \mathrm{p}<0.1,{ }^{* *} \mathrm{p}<0.05,{ }^{* * *} \mathrm{p}<0.01$ 
Table A.24: Second generation, age 45 and above - Additional control variables - Withincountry variation only

$(1) \quad(2)$

(3)

\begin{tabular}{|c|c|c|c|c|c|c|}
\hline Total fertility rate & 0.43 & $(1.04)$ & 1.09 & $(1.13)$ & -5.47 & $(12.32)$ \\
\hline Age & 0.04 & $(0.03)$ & 0.05 & $(0.04)$ & 0.38 & $(0.55)$ \\
\hline Medium education & $-1.09^{* *}$ & $(0.53)$ & $-1.04^{*}$ & $(0.53)$ & 0.10 & $(0.62)$ \\
\hline High education & $-1.58^{* * *}$ & $(0.49)$ & $-1.47^{* * *}$ & $(0.50)$ & -0.48 & $(0.97)$ \\
\hline Married & $0.58^{*}$ & $(0.32)$ & & & $-1.21^{* *}$ & $(0.52)$ \\
\hline Only foreign nationality & 0.15 & $(0.30)$ & & & $1.97^{*}$ & $(1.05)$ \\
\hline Employed & & & 0.05 & $(0.40)$ & 0.71 & $(1.03)$ \\
\hline Household net income & & & -0.01 & $(0.07)$ & 0.11 & $(0.19)$ \\
\hline GDP per capita & & & & & 0.42 & $(3.85)$ \\
\hline Intercept & -1.07 & $(2.49)$ & -2.45 & $(2.69)$ & -4.93 & $(25.04)$ \\
\hline Bundesland Fixed Effects & Yes & & Yes & & Yes & \\
\hline Country of Origin Fixed Effects & Yes & & Yes & & Yes & \\
\hline $\mathrm{R}^{2}$ & 0.43 & & 0.42 & & 0.88 & \\
\hline Observations & 93 & & 89 & & 29 & \\
\hline
\end{tabular}

Note: Mikrozensus 2008. The dependent variable is the number of children. The models are estimated using Ordinary Least Squares. Standard errors clustered at the country-year of birth level. Medium education: upper secondary degree or some professional training; High education: tertiary education; omitted reference category: no degree or the equivalent of the German Hauptschule and Realschule. Income in 1000 euros; measured in the month before the interview. Omitted reference category for 'only foreign nationality': German nationality or both German and foreign nationality. GDP per capita in constant US dollars, base year 2000. Unit of measurement: 1000 dollars/year. ${ }^{*} \mathrm{p}<0.1,{ }^{* *} \mathrm{p}<0.05, * * * \mathrm{p}<0.01$ 
Table A.25: Second generation, age 15 and above - Additional control variables - Withincountry variation only

\begin{tabular}{|c|c|c|c|c|c|c|}
\hline \multirow[b]{2}{*}{ Total fertility rate } & \multicolumn{2}{|c|}{$(1)$} & \multicolumn{2}{|c|}{$(2)$} & \multicolumn{2}{|c|}{$(3)$} \\
\hline & $0.15^{* * *}$ & $(0.05)$ & $0.21^{* * *}$ & $(0.05)$ & $0.14^{* *}$ & $(0.07)$ \\
\hline Age & $0.05^{* * *}$ & $(0.02)$ & $0.16^{* * *}$ & $(0.02)$ & $0.04^{*}$ & $(0.02)$ \\
\hline $\mathrm{Age}^{2}$ & -0.00 & $(0.00)$ & $-0.00^{* * *}$ & $(0.00)$ & 0.00 & $(0.00)$ \\
\hline Medium education & $-0.32^{* * *}$ & $(0.04)$ & $-0.38 * * *$ & $(0.04)$ & $-0.27 * * *$ & $(0.04)$ \\
\hline High education & $-0.79 * * *$ & $(0.08)$ & $-0.96^{* * *}$ & $(0.09)$ & $-0.74^{* * *}$ & $(0.09)$ \\
\hline Married & $0.91^{* * *}$ & $(0.05)$ & & & $0.86^{* * *}$ & $(0.06)$ \\
\hline Only foreign nationality & $0.04^{*}$ & $(0.03)$ & & & 0.01 & $(0.03)$ \\
\hline Employed & & & $-0.32^{* * *}$ & $(0.04)$ & $-0.27 * * *$ & $(0.04)$ \\
\hline Household net income & & & $0.02^{*}$ & $(0.01)$ & 0.01 & $(0.01)$ \\
\hline GDP per capita & & & & & 0.00 & $(0.02)$ \\
\hline Intercept & $-1.04^{* * *}$ & $(0.20)$ & $-2.46^{* * *}$ & $(0.25)$ & $-0.88^{* *}$ & $(0.43)$ \\
\hline Bundesland Fixed Effects & Yes & & Yes & & Yes & \\
\hline Country of Origin Fixed Effects & Yes & & Yes & & Yes & \\
\hline $\mathrm{R}^{2}$ & 0.57 & & 0.47 & & 0.60 & \\
\hline Observations & 3532 & & 3234 & & 2764 & \\
\hline
\end{tabular}
Note: Mikrozensus 2008. The dependent variable is the number of children. The models are estimated using Ordinary
Least Squares. Standard errors clustered at the country-year of birth level. Medium education: upper secondary degree
or some professional training; High education: tertiary education; omitted reference category: no degree or the equivalent
of the German Hauptschule and Realschule. Income in 1000 euros; measured in the month before the interview. Omitted
reference category for 'only foreign nationality': German nationality or both German and foreign nationality. GDP per
capita in constant US dollars, base year 2000 . Unit of measurement: 1000 dollars/year. ${ }^{*}$ p $<0.1,{ }^{* *} p<0.05,{ }^{* * *}$ p $<0.01$

Table A.26: Generations 1.5 and 2, age 45 and above - Additional control variables Within-country variation only
(1)
$(2)$
(3)

\begin{tabular}{|c|c|c|c|c|c|c|}
\hline Total fertility rate & 0.17 & $(0.30)$ & 0.16 & $(0.32)$ & 0.16 & $(2.35)$ \\
\hline Age & 0.00 & $(0.02)$ & 0.00 & $(0.02)$ & 0.02 & $(0.11)$ \\
\hline Medium education & $-0.49 * * *$ & $(0.12)$ & $-0.56^{* * *}$ & $(0.13)$ & $-0.44^{*}$ & $(0.23)$ \\
\hline High education & $-1.00 * * *$ & $(0.20)$ & $-1.22^{* * *}$ & $(0.26)$ & $-1.72^{* * *}$ & $(0.31)$ \\
\hline Married & $0.38^{* * *}$ & $(0.12)$ & & & -0.15 & $(0.22)$ \\
\hline Only foreign nationality & 0.05 & $(0.13)$ & & & 0.15 & $(0.23)$ \\
\hline Employed & & & -0.11 & $(0.14)$ & -0.37 & $(0.24)$ \\
\hline Household net income & & & $0.11^{* *}$ & $(0.05)$ & 0.13 & $(0.09)$ \\
\hline GDP per capita & & & & & -0.34 & $(0.59)$ \\
\hline Intercept & $1.41^{*}$ & $(0.73)$ & $1.48^{*}$ & $(0.79)$ & 3.10 & $(5.87)$ \\
\hline Bundesland Fixed Effects & Yes & & Yes & & Yes & \\
\hline Country of Origin Fixed Effects & Yes & & Yes & & Yes & \\
\hline $\mathrm{R}^{2}$ & 0.27 & & 0.26 & & 0.35 & \\
\hline Observations & 495 & & 469 & & 155 & \\
\hline
\end{tabular}

Note: Mikrozensus 2008. The dependent variable is the number of children. The models are estimated using Ordinary Least Squares. Standard errors clustered at the country-year of birth level. Medium education: upper secondary degree or some professional training; High education: tertiary education; omitted reference category: no degree or the equivalent of the German Hauptschule and Realschule. Income in 1000 euros; measured in the month before the interview. Omitted reference category for 'only foreign nationality': German nationality or both German and foreign nationality. GDP per capita in constant US dollars, base year 2000. Unit of measurement: 1000 dollars/year. ${ }^{*} \mathrm{p}<0.1,{ }^{* *} \mathrm{p}<0.05,{ }^{* * *} \mathrm{p}<0.01$ 


\section{A.6 TFR from single years}

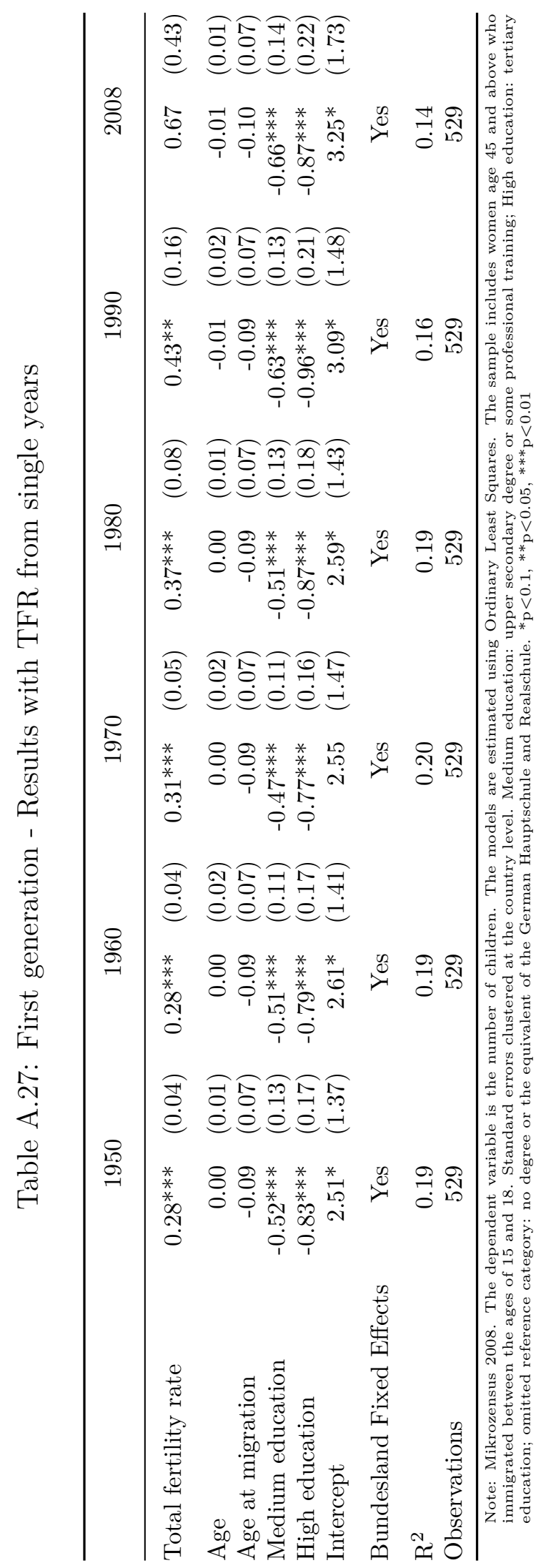




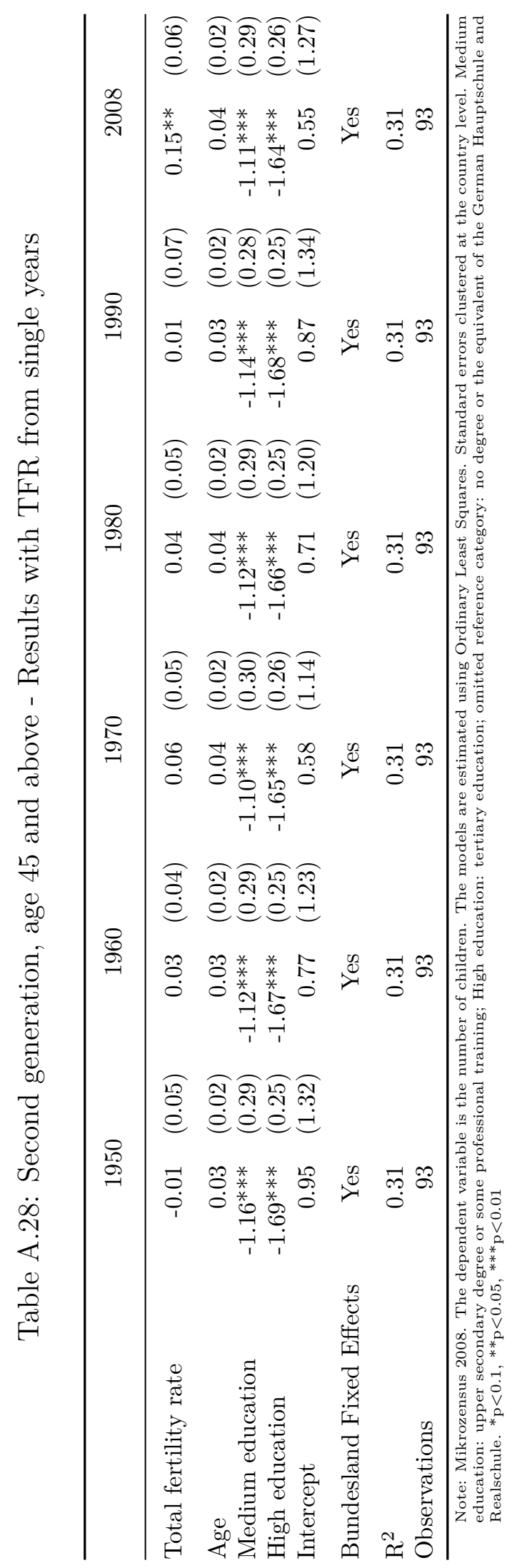




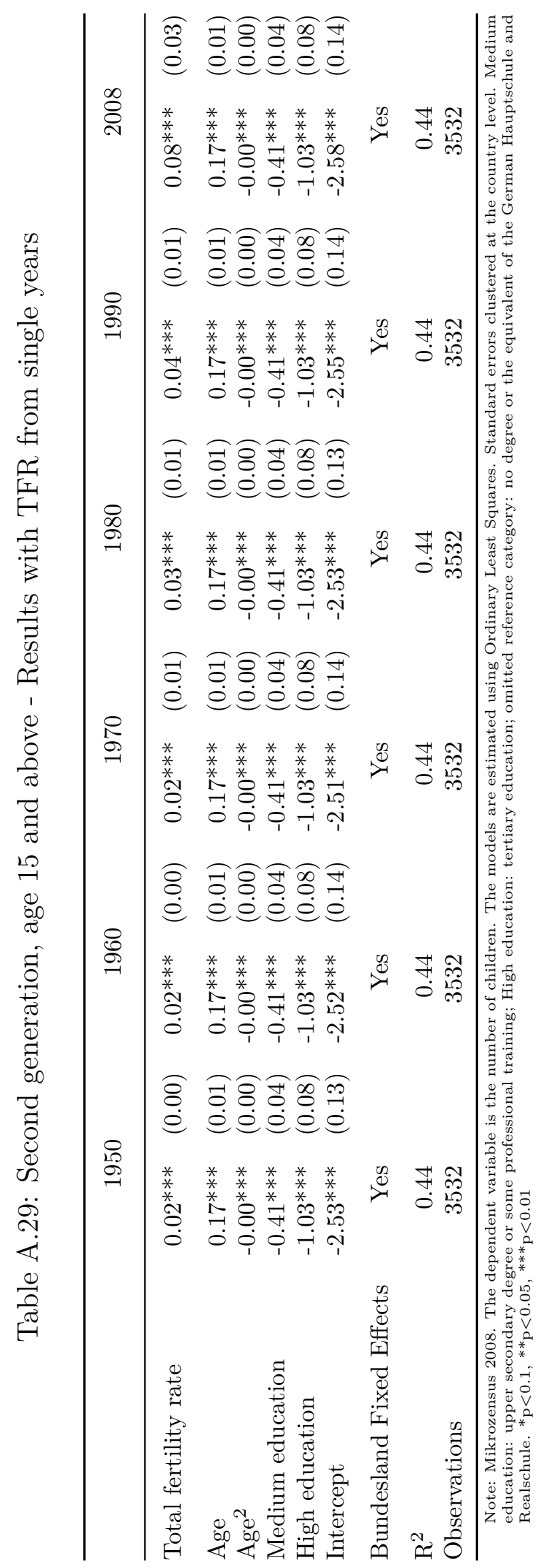




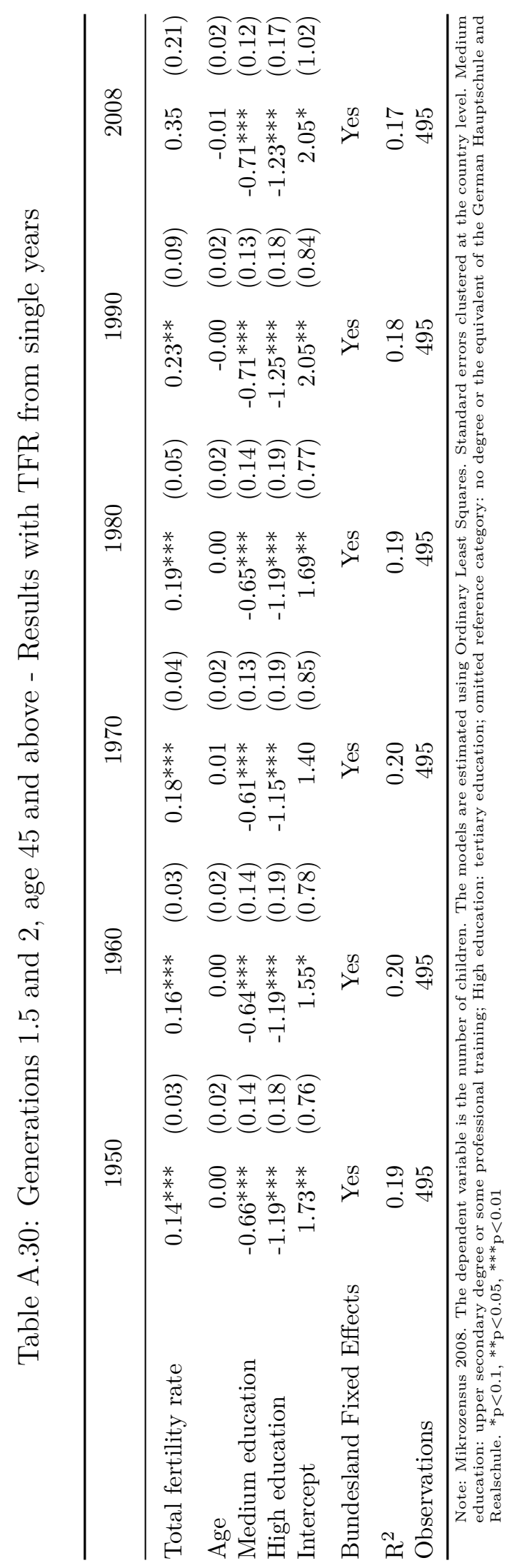


A.7 Fertility norms from the World Values Survey 1990

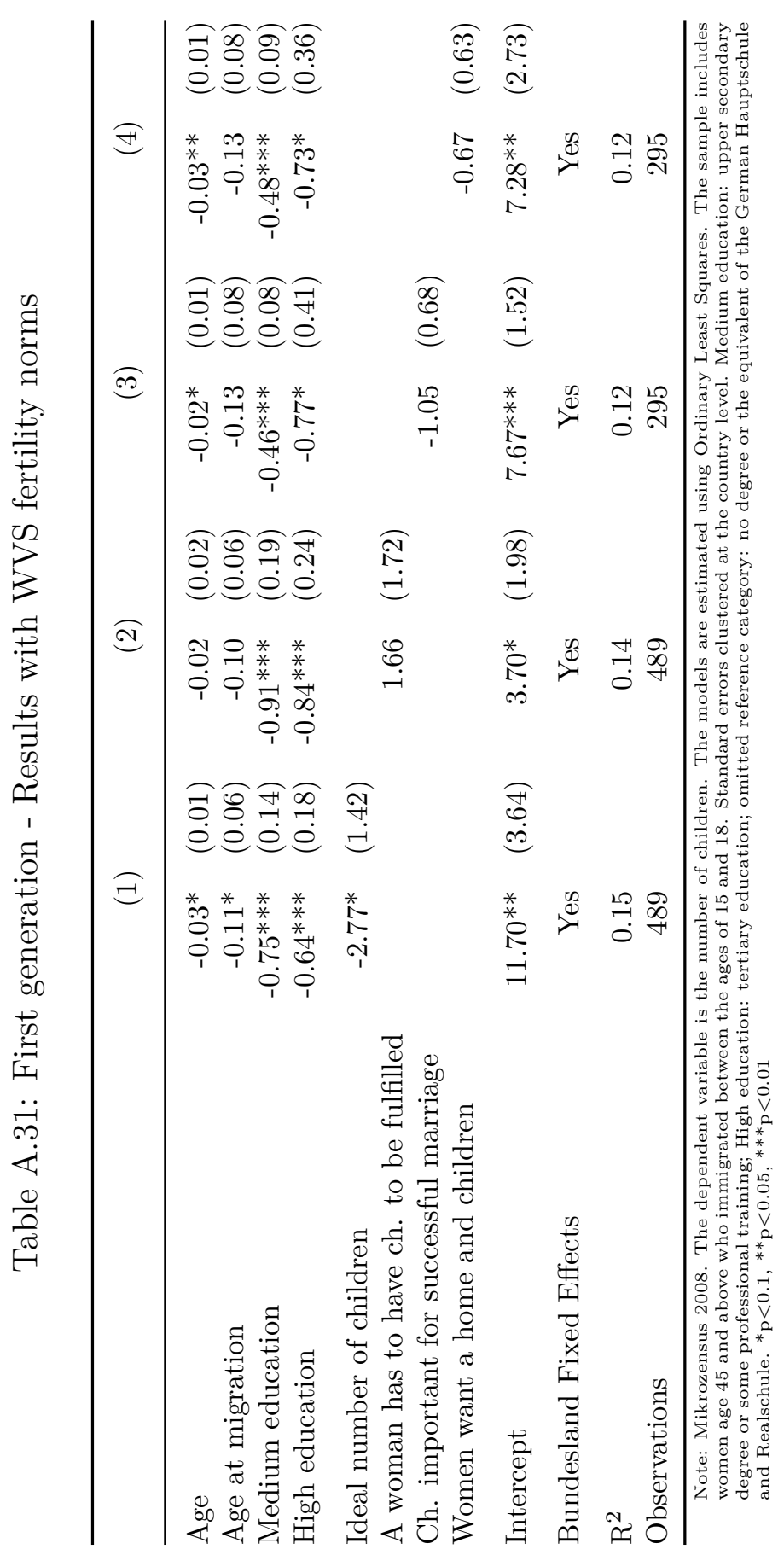




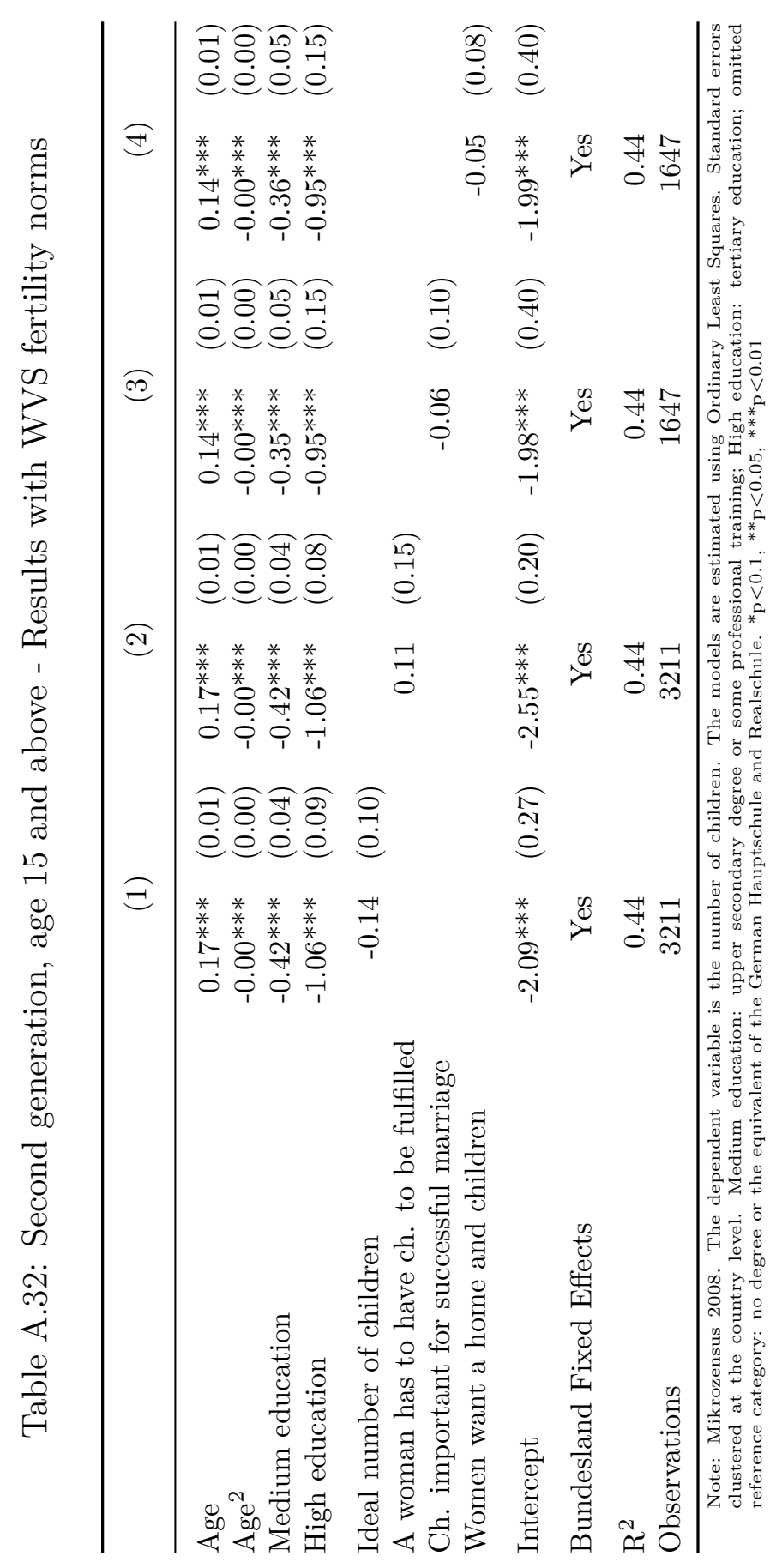




\section{A.8 Cohort fertility rates}

Table A.33: First generation - Results with cohort fertility rates

(1)

$(2)$

$(3)$

\begin{tabular}{|c|c|c|c|c|c|c|}
\hline Completed cohort fertility & $0.56^{* * *}$ & $(0.06)$ & $0.52^{* * *}$ & $(0.07)$ & $0.97^{* * *}$ & $(0.36)$ \\
\hline Age & & & -0.01 & $(0.01)$ & $-0.02 *$ & $(0.01)$ \\
\hline Age at migration & & & -0.09 & $(0.06)$ & -0.09 & $(0.06)$ \\
\hline Medium education & & & $-0.51^{* * *}$ & $(0.12)$ & $-0.35^{* * *}$ & $(0.13)$ \\
\hline High education & & & $-0.72^{* * *}$ & $(0.25)$ & $-0.58^{* *}$ & $(0.24)$ \\
\hline Intercept & $0.82^{* * *}$ & $(0.18)$ & $3.02^{* *}$ & $(1.30)$ & 2.11 & $(1.38)$ \\
\hline Bundesland Fixed Effects & No & & Yes & & Yes & \\
\hline Country of Origin Fixed Effects & No & & No & & Yes & \\
\hline $\mathrm{R}^{2}$ & 0.15 & & 0.21 & & 0.24 & \\
\hline Observations & 515 & & 515 & & 515 & \\
\hline
\end{tabular}

Note: Mikrozensus 2008. The dependent variable is the number of children. The models are estimated using Ordinary Least Squares. The sample includes women age 45 and above who immigrated between the ages of 15 and 18 . Standard errors clustered at the country-birthyear level. Medium education: upper secondary degree or some professional training; High education: tertiary education; omitted reference category: no degree or the equivalent of the German Hauptschule and Realschule. ${ }^{*} \mathrm{p}<0.1,{ }^{* *} \mathrm{p}<0.05,{ }^{* * *} \mathrm{p}<0.01$

Table A.34: Second generation, age 45 and above - Results with cohort fertility rates

(1)

$(2)$

(3)

\begin{tabular}{|c|c|c|c|c|c|c|}
\hline Completed cohort fertility & 0.36 & $(0.23)$ & -0.03 & $(0.23)$ & -0.65 & $(1.07)$ \\
\hline Age & & & 0.04 & $(0.03)$ & 0.08 & $(0.05)$ \\
\hline Medium education & & & $-1.12^{* *}$ & $(0.44)$ & $-1.20^{* *}$ & $(0.52)$ \\
\hline High education & & & $-1.73^{* * *}$ & $(0.42)$ & $-1.83^{* * *}$ & $(0.51)$ \\
\hline Intercept & 0.76 & $(0.52)$ & 0.86 & $(2.02)$ & 0.17 & $(1.97)$ \\
\hline Bundesland Fixed Effects & No & & Yes & & Yes & \\
\hline Country of Origin Fixed Effects & No & & No & & Yes & \\
\hline $\mathrm{R}^{2}$ & 0.02 & & 0.30 & & 0.38 & \\
\hline Observations & 89 & & 89 & & 89 & \\
\hline
\end{tabular}

Note: Mikrozensus 2008. The dependent variable is the number of children. The models are estimated using Ordinary Least Squares. Standard errors clustered at the country-birthyear level. Medium education: upper secondary degree or some professional training; High education: tertiary education; omitted reference category: no degree or the equivalent of the German Hauptschule and Realschule. ${ }^{*} \mathrm{p}<0.1,{ }^{* *} \mathrm{p}<0.05,{ }^{* * *} \mathrm{p}<0.01$ 
Table A.35: Second generation, age 15 and above - Results with cohort fertility rates

(1)

$(2)$

(3)

\begin{tabular}{|c|c|c|c|c|c|c|}
\hline Completed cohort fertility & $0.58^{* * *}$ & $(0.09)$ & 0.03 & $(0.06)$ & -0.06 & $(0.56)$ \\
\hline Age & & & $0.15^{* * *}$ & $(0.02)$ & $0.14^{* * *}$ & $(0.02)$ \\
\hline $\mathrm{Age}^{2}$ & & & $-0.00^{* * *}$ & $(0.00)$ & $-0.00 * * *$ & $(0.00)$ \\
\hline Medium education & & & $-0.37 * * *$ & $(0.05)$ & $-0.36^{* * *}$ & $(0.05)$ \\
\hline High education & & & $-0.96^{* * *}$ & $(0.10)$ & $-0.94 * * *$ & $(0.10)$ \\
\hline Intercept & $-0.49^{* * *}$ & $(0.17)$ & $-2.22^{* * *}$ & $(0.24)$ & $-1.94^{* *}$ & $(0.96)$ \\
\hline Bundesland Fixed Effec & No & & Yes & & Yes & \\
\hline Country of Origin Fixed Effects & No & & No & & Yes & \\
\hline $\mathrm{R}^{2}$ & 0.04 & & 0.45 & & 0.45 & \\
\hline Observations & 1856 & & 1856 & & 1856 & \\
\hline
\end{tabular}

Note: Mikrozensus 2008. The dependent variable is the number of children. The models are estimated using Ordinary

Least Squares. Standard errors clustered at the country-birthyear level. Medium education: upper secondary degree or

some professional training; High education: tertiary education; omitted reference category: no degree or the equivalent

of the German Hauptschule and Realschule. ${ }^{*} \mathrm{p}<0.1, * * \mathrm{p}<0.05, * * * \mathrm{p}<0.01$

Table A.36: Generations 1.5 and 2, age 45 and above - Results with cohort fertility rates

(1)

(2)

(3)

\begin{tabular}{|c|c|c|c|c|c|c|}
\hline Completed cohort fertility & $0.36^{* * *}$ & $(0.06)$ & $0.27^{* * *}$ & $(0.07)$ & $-1.34^{* *}$ & $(0.58)$ \\
\hline Age & & & -0.00 & $(0.01)$ & $0.03^{* *}$ & $(0.02)$ \\
\hline Medium education & & & $-0.60 * * *$ & $(0.11)$ & $-0.52 * * *$ & $(0.12)$ \\
\hline High education & & & $-1.10^{* * *}$ & $(0.20)$ & $-1.03^{* * *}$ & $(0.22)$ \\
\hline Intercept & $0.99 * * *$ & $(0.17)$ & $1.87^{* *}$ & $(0.74)$ & $2.82^{* * *}$ & $(0.86)$ \\
\hline Bundesland Fixed Effects & No & & Yes & & Yes & \\
\hline Country of Origin Fixed Effects & No & & No & & Yes & \\
\hline $\mathrm{R}^{2}$ & 0.05 & & 0.18 & & 0.21 & \\
\hline Observations & 484 & & 484 & & 484 & \\
\hline
\end{tabular}

Note: Mikrozensus 2008. The dependent variable is the number of children. The models are estimated using Ordinary Least Squares. Standard errors clustered at the country-birthyear level. Medium education: upper secondary degree or some professional training; High education: tertiary education; omitted reference category: no degree or the equivalent of the German Hauptschule and Realschule. ${ }^{*} \mathrm{p}<0.1,{ }^{* *} \mathrm{p}<0.05,{ }^{* * *} \mathrm{p}<0.01$ 